Manuela Carneiro

da Silva 

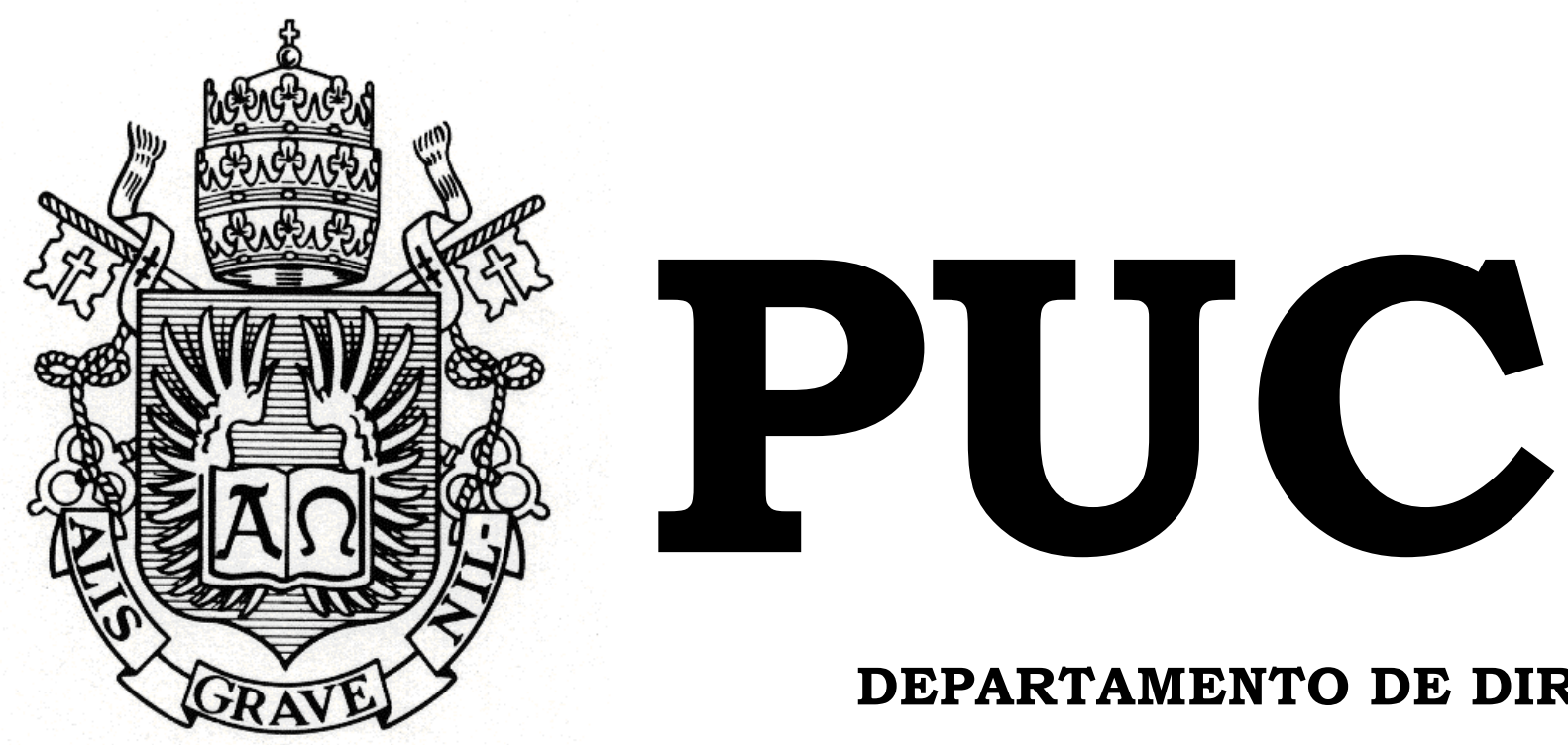

DEPARTAMENTO DE DIREITO

\title{
A CRISE E A REGULAÇÃO FINANCEIRA
}

\author{
por \\ MANUELA CARNEIRO DA SILVA \\ ORIENTADOR: JULIAN FONSECA PEÑA CHEDIAK \\ 2009.2
}

PONTIFÍCIA UNIVERSIDADE CATÓLICA DO RIO DE JANEIRO

RUA MARQUÊS DE SÃO VICENTE, 225 - CEP 22453-900

RIO DE JANEIRO - BRASIL 


\section{A CRISE E A REGULAÇÃO FINANCEIRA}

por

MANUELA CARNEIRO DA SILVA

Monografia apresentada ao Departamento de Direito da Pontificia Universidade Católica do Rio de Janeiro (PUC-Rio) para a obtenção do Título de Bacharel em Direito.

Orientador: Julian Fonseca Peña Chediak 
À minha mãe, por tudo. 
Meus agradecimentos aos amigos e chefes de Pinheiro Neto Advogados e de Bocater, Camargo, Costa e Silva Advogados Associados, que tanto me ensinaram;

às amigas de PUC que estiveram ao meu lado ao longo desses anos todos;

ao Thiago, não só pelo companheirismo, mas também pelos pacientes ensinamentos econômicos;

ao Julian, pela amizade e brilhantismo;

a todos aqueles que de alguma maneira contribuíram para que um dia pudesse me tornar bacharel, seja academicamente, seja com sua amizade ou com seu carinho.

Agradeço principalmente à minha mãe, a quem decido meu primeiro trabalho acadêmico. 


\section{Resumo}

Em tempos de crise, é importante que saibamos aprender com o ocorrido em outros países para que possamos preparar nossa estrutura regulatória e corrigir eventuais falhas. Neste trabalho serão discutidas as bases teóricas para que se possa entender o que aconteceu e discutir o que pode ser feito no futuro.

No capítulo um, será feita uma análise da crise, seus motivos determinantes, e sua contaminação mundial. No capítulo dois, serão discutidas as estruturas teóricas para a supervisão financeira para, posteriormente, analisar sua aplicação nos Estados Unidos e no Brasil (tendo em vista que nenhuma delas é aplicada em perfeita consonância com a teoria, e sim adaptada em função dos movimentos históricos e políticos de cada país).

No capítulo três, ao final, será analisada a falha na regulação dos bancos de investimento americanos e em que medida tal falha, ao menos teoricamente, não teria ocorrido no Brasil.

Palavras-chave: Crise. Mercado de Capitais. Mercado Financeiro. Regulação. Bancos de Investimento. 


\section{Abstract}

In times of crisis, it is important to learn from the events that took place in other countries in order to prepare our supervision structure and correct possible flaws. This monographic work will analyze the theoretical basis necessary to understand what happened and discuss what may be done in the future.

Chapter one will overview the crisis, its determining motives and its worldwide spread. Chapter two will discuss the theoretical structures for financial supervision and then the actual way it is applied in the United States and in Brazil (taking into account that neither of them are applied in perfect coherence with theory, being its application a result of the historical and political movements of each country).

Chapter three will then analyze the regulatory gap of the american investment banking regulation and how Brazil, at least in theory, is not subject to such failure.

Keywords: Crisis. Capital Market. Financial Market. Regulação. Investment Banks. 


\section{Sumário}

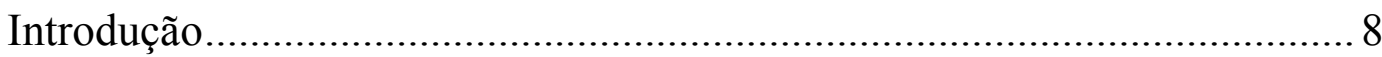

1. A "crise do início do século" ............................................................ 12

2. A regulação do mercado financeiro nos EUA e no Brasil ......................26

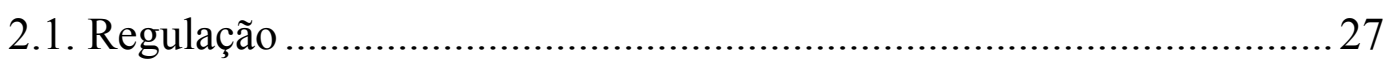

2.2. A estrutura da supervisão financeira .............................................. 31

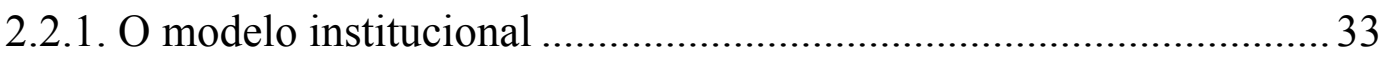

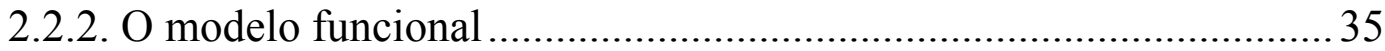

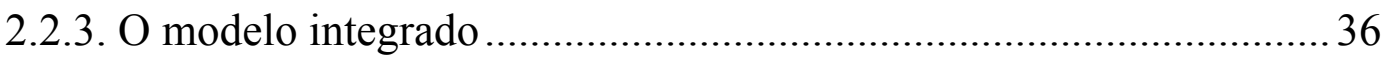

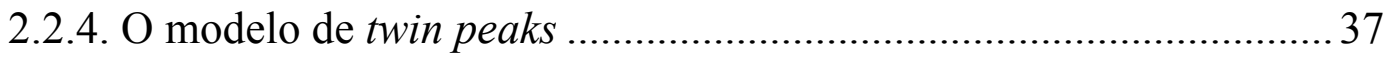

2.3. A estrutura para a supervisão financeira nos Estados Unidos.............. 38

2.4. A estrutura para a supervisão financeira no Brasil............................. 46

3. A crise e a regulação financeira ...................................................5 52

3.1. A competência para regular os bancos de investimento nos Estados

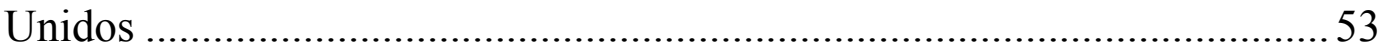

3.2. A competência para regular os bancos de investimento no Brasil .......57

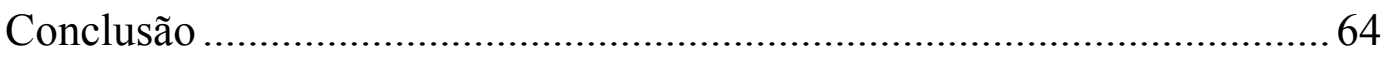

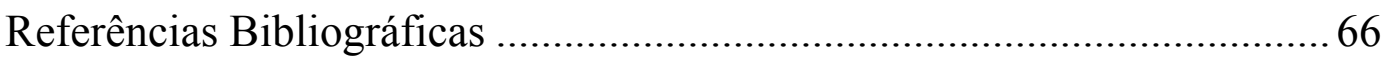




\section{Abreviações}

BCB - Banco Central do Brasil

$\mathrm{CDO}$ - collaterized debt obligation

CDS - credit default swaps

CFTC - Commodity Futures Trading Comission

CMN - Conselho Monetário Nacional

CNSP - Conselho Nacional de Seguros Privados

COAF - Conselho de Controle de Atividades Financeiras

COREMEC - Comitê de Regulação e Fiscalização dos Mercados

Financeiro, de Capitais, de Seguros, de Previdência e Capitalização

CPC - Conselho de Previdência Complementar

CVM - Comissão de Valores Mobiliários

Fannie Mae - Federal National Mortgage Association

FDIC - Federal Deposit Insurance Corporation

FED - Federal Reserve Board

FFIEC - Federal Financial Institutions Examination Council

Freddie Mac - Federal Home Loan Mortgage Corporation

IRB - Instituto de Resseguros do Brasil

MBS - mortgage-backed security

MBS CDO - mortgage-backed security collaterized debt obligation

NCUA - National Credit Union Association

OCC - Office of the Comptroller of the Currency

OTS - Office of Thrift Supervision

PWG - President's Working Group on Financial Markets

SEC - Securities and Exchange Comission

SPC - Secretaria de Previdência Complementar

SPE - special purpose entity ou sociedade de propósito específico

SUSEP - Superintendência de Seguros Privados 


\section{Introdução}

"The problems of our economy have occurred not as an outgrowth of laissezfaire, unbridled competition. They have occurred under the guidance of federal agencies, and under the umbrella of federal regulations."

Sen. Ted Kennedy, 1978

Chamando a atenção dos agentes de mercado há anos, a mais recente crise financeira (já chamada por alguns de a "crise do início do século") se tornou assunto de preocupação mundial em setembro de 2008, com os eventos que se iniciaram com a falência do banco de investimento Lehman Brothers.

De uma conexão entre o mercado financeiro e o mercado de crédito que, em princípio, pareceria proveitosa (e ainda pode ser considerada como tal dependendo do ponto de vista), somada à criação de novos instrumentos financeiros e à falta de supervisão prudencial efetiva sobre os bancos de investimento, a crise escalou para proporções difíceis de ser estimadas (se é que já o podem ser). O mercado de capitais nacional mais desenvolvido do mundo via-se, antes da crise, diante de um paradoxo: desregular para atrair investimentos ou regular para evitar falhas no sistema? Optou-se pela primeira das afirmações mas hoje, diante dos fatos ocorridos, há um clamor para que se opte por uma regulação cada vez mais dura e incisiva.

Este trabalho busca fornecer as bases conceituais e doutrinárias para que se possa proceder ao debate ilustrado do tema "crise e regulação". Não se pretende aqui esgotá-lo, o que seria indevido em um trabalho de final de curso, mas sim fornecer instrumentos de reflexão e discussão para aquele que nele se interesse.

O foco principal do trabalho é a regulação dos bancos de investimento. Para que se entenda o quer ocorreu, se passará por uma breve 
e objetiva descrição da crise e os motivos que levaram à ruína dos bancos americanos. A partir daí, será possível discutir os sistemas regulatórios existentes no mundo (no que diz respeito à divisão de competências regulatórias), e traçar um paralelo entre o sistema de regulação do mercado financeiro americano e brasileiro.

Ora, embora vivamos em um mundo globalizado, cada país possui suas especificidades econômicas e culturais e, em última instância, por mais globalizados e abertos que sejam, cada mercado de capitais possui uma história e um desenvolvimento próprio, a justificarem suas diferentes características. Não se pode esquecer portanto, quando da referida comparação, que o desenvolvimento do mercado de capitais americano (e por conseqüência, mundial) foi uma história de sucesso que gerou renda, empregos e desenvolvimento humano para o mundo.

Crises são em certos momentos históricos, inevitáveis (e para muitos doutrinadores, eventos que ocorrerão sucessivamente na história mundial). O que regulador deve tentar compreender é que embora devam ser evitadas, as crises não devem ser impedidas se isso significar reduzir a capacidade de desenvolvimento do mercado de capitais. As crises geram conseqüências negativas imensuráveis, sem dúvida, mas todo o cuidado é pouco quando se trata de regulação: regular, sem dúvida; "engessar", jamais. Assim, o que se propõe não é que a otimização da regulação venha ao custo de uma regulação exarcebada, mas sim a análise consciente do tema para o fortalecimento da estrutura legal.

Por último, a terceira parte deste trabalho visa discutir o que ocorreu com a regulação dos bancos de investimento nos Estados Unidos, que restaram mal regulados, e em que medida o Brasil se encontra protegido, ao menos em tese, de tal ocorrência. Vale ressaltar, neste aspecto, que somente será analisado um dos inúmeros problemas apontados com o surgimento da crise: a regulação dos bancos de investimento. Esse problema será abordado no que diz respeito à existência ou não de competência regulatória para supervisioná-los, e não se e em que medida a supervisão é eficaz. Discutir- 
se-á somente as competências dos órgãos, e não a eficácia de suas normas. Assim, não será analisada a eficácia do poder punitivo do regulador e de suas normas.

O presente trabalho buscará analisar e discutir essas questões, não se propondo, no entanto, a dar respostas definitivas e imutáveis, pois o processo de elaboração de normas e aliás, todos os processos científicos (embora se diga o contrário), se devem não tanto a encontrar as respostas, mas sim a fazer as perguntas corretas.

Além disso, foge do escopo deste trabalho a análise puramente econômica de fatos ocorridos ou de fenômenos a ocorrer (como a eventual repercussão econômica da mudança de uma norma). Quando possível, pretende-se aprofundar esse trabalho também sob a perspectiva econômica, o que infelizmente não é possível em uma monografia de final de curso de Direito.

Este trabalho busca então fornecer as bases para a análise da eficiência ou não da supervisão do sistema financeiro visando alertar os estudiosos do Direito para a necessidade de aprendermos com os erros alheios através do preparo e fortalecimento do sistema regulatório nacional.

Para se atingir tais objetivos, utilizar-se-á basicamente do estudo histórico e analítico. No que diz respeito ao estudo histórico, o estudo buscará abordar os acontecimentos nos Estados Unidos e as análises de diferentes autores sobre os mesmos. Além disso, será através da análise histórica que se formará a base para a discussão relativa a regulação dos bancos de investimento.

No contexto do estudo analítico, se buscou analisar as causas históricas do problema e discutir uma das falhas apontadas para a crise e em que medida o Brasil está ou não, em tese, protegido de tal falha.

$\mathrm{O}$ interesse da autora pelo tema deve-se ao fato de ter trabalhado com Direito Societário e de Mercado de Capitais em Pinheiro Neto Advogados e, posteriormente, em Bocater, Camargo, Costa e Silva Advogados Associados. Além disso, a autora possui paixão pelos assuntos 
econômicos, pretendendo, quando possível, fazer uma pós-graduação em finanças corporativas e aplicar para o LL.M. nos Estados Unidos, onde pretende estudar a matéria desta monografia com mais profundidade.

Ainda, a autora é monitora do Prof. Julian Chediak, grande responsável por esse amor pela regulação de mercado de capitais e por todo o seu desenvolvimento acadêmico. Mais ainda: a autora cresceu discutindo assuntos como esse com sua mãe, hoje aposentada do BNDES e com as pessoas mais próximas a si (também estudiosos de economia). 


\section{A "crise do início do século"}

Há quem diga que essa é a maior crise que o mundo enfrenta desde a Grande Depressão ${ }^{1}$. Estimativas do Fundo Monetário Internacional - "FMI" ou "IMF" apontam que serão necessários de US\$ 275 bilhões (duzentos e setenta e cinco bilhões de dólares) a US\$ 500 bilhões (quinhentos bilhões de dólares), além de tudo o que já foi gasto (ou investido) apenas para a recapitalização dos bancos americanos ${ }^{2}$. Para os bancos europeus (excluídos os bancos do Reino Unido) seriam necessários de US\$ 475 bilhões (quatrocentos e setenta e cinco bilhões de dólares) a 950 bilhões (novecentos e cinqüenta bilhões de dólares). Já para os bancos ingleses, seria necessário ainda o investimento de US\$ 125 bilhões (cento e vinte e cinco bilhões de dólares) a US\$ 250 bilhões (duzentos e cinqüenta bilhões de dólares).

A título de ilustração, vejamos a tabela abaixo em que o FMI mede o tamanho da crise atual em comparação com as crises anteriores, tendo por base o produto interno bruto ("PIB" ou "GDP") americano:

\section{Tabela I - Tensão nas Economias Avançadas}

(fonte: FMI. World economic outlook: a survey by the staff of the International Monetary

Fund. Washington, DC: International Monetary Fund. April, 2009. p. 137)

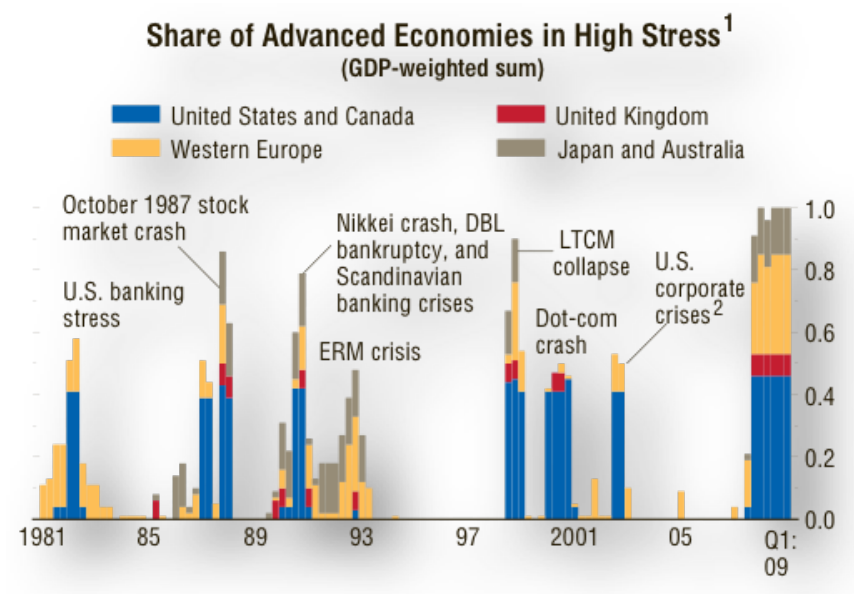

\footnotetext{
1 BERNANKE, Ben S. Reflections on a year of crisis. Discurso proferido no Simpósio Anual do Federal Reserve Bank de Kansas City, Jackson, Wyoming, em 21.08.2009.

${ }^{2}$ World economic outlook: a survey by the staff of the International Monetary Fund. Washington,
} 
Essas são, em curtas palavras, as medidas da crise.

Mas, o que é uma crise? Como começou? Quais foram os erros apontados? Como podemos evitá-la? Qual o papel do regulador no meio desse turbilhão?

Para responder a tais questões, é necessário partir de algumas premissas sobre as crises, levantadas pela maioria dos autores da área:

I. As crises são cíclicas e voltarão a ocorrer, inevitavelmente.

A esse respeito, muito ilustrativa é a conclusão do próprio FMI que demonstra, em gráficos, o que executivos como David Altig e Raghuram Rajan $^{3}$ concluíram: as crises vão e voltam, são inevitáveis; o que podemos fazer é assumir os erros e estar preparados.

II. vivemos em um mundo globalizado, de modo que crises em um país afetam diversos outros; os mercados estão interconectados.

Sobre essa conexão óbvia, posto que sentida pelo mais comum dos cidadãos, ilustrativo também é o gráfico elaborado pelo FMI, que explica tecnicamente as maneiras pelas quais essa difusão pode se operar:

\section{Tabela II - Transferência da Tensão Financeira}

(fonte: FMI. World economic outlook: a survey by the staff of the International Monetary Fund. Washington, DC: International Monetary Fund. April, 2009. p. 143)

DC: International Monetary Fund. April, 2009. Executive summary, p. xvii.

${ }^{3}$ ALTIG, David. A nova regulação para gerenciamento de riscos de crédito pós-crise subprime. Apresentação feita no 4o Congresso Internacional do Mercado Financeiro e de Capitais, organizado pela BM\&F Bovespa. Campos do Jordão, São Paulo, em 29.08.2009. Disponível em http://www.bmf.com.br/portal/pages/congresso/2009/apresentacoes.asp.

RAJAN, Raghuram. Recriando o sistema financeiro. Apresentação feita no 4o Congresso Internacional do Mercado Financeiro e de Capitais, organizado pela BM\&F Bovespa. Campos do Jordão, São $\quad$ Paulo, $\quad$ em $\quad 29.08 .2009 . \quad$ Disponível em http://www.bmf.com.br/portal/pages/congresso/2009/apresentacoes.asp. 


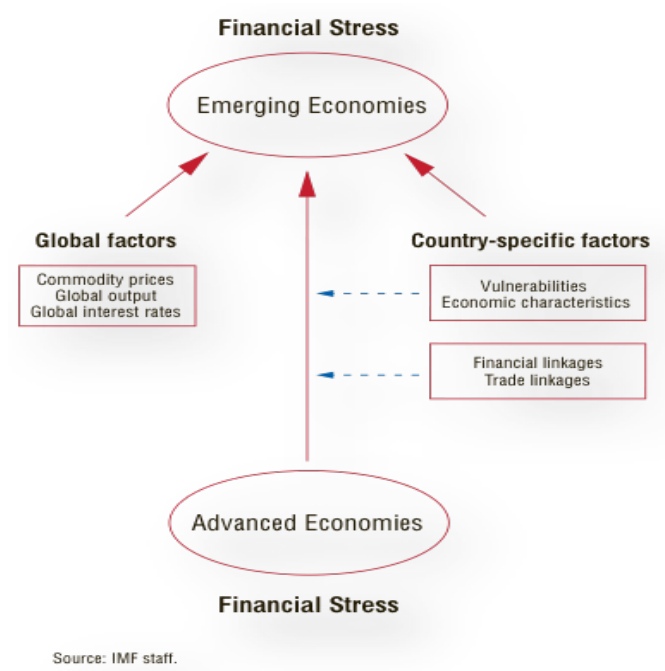

III - a crise que vivemos não é resultado de um só erro ou de um só problema: foi resultado de uma sucessão de erros, que hoje podem ser visualizados em parte.

Esse ponto se tornará claro ao final deste capítulo, quando teremos explicado o que foi a crise atual, como ocorreu e quais as suas causas.

Uma vez aceitas tais premissas, vê-se que os autores explicam a crise através de uma sucessão de eventos históricos que, colocados em perspectiva, pretendem explicar o que ocorreu. Nas próximas páginas, será feito um esforço de sintetização do complexo emaranhado de operações e possíveis erros que levou o mundo (e principalmente os Estados Unidos), à situação em que se encontra. Cabe mais uma vez ressaltar que não se trata aqui de uma análise econômica strictu sensu do que ocorreu, e sim de uma releitura daquilo que foi apontado pelos autores ${ }^{4}$.

\footnotetext{
${ }^{4}$ Para a cronologia da crise, seus motivos determinantes e explicações básicas, nos basearemos em HELLWIG, Martin. Systemic risk in the financial sector: an analysis of the subprime-mortgage financial crisis. Disponível em: http://www.coll.mpg.de/abst2008 43.html. Acesso em 27.03.2009. Ainda, algumas informações deste capítulo, principalmente no que diz respeito a análises empíricas, serão retiradas de TAYLOR, John B. The financial crisis and the policy responses: an empirial analysis of what went wrong. Disponível em: http://www.nber.org/papers/w14631. Acesso em 27.03.2009.

Para mais informações sobre a crise, ver: BRUNNERMEIER, Markus K. Deciphering the liquidity and credit crunch. Disponível em: http://www.nber.org/papers/w14612; FRATIANNI, Michele U., Financial Crises, Safety Nets and Regulation. Disponível em:
} 
Como em toda crise, a história sempre começa com incentivos mal utilizados e com uma bolha que infla até que seja seguida por sua explosão. A economia americana (e mundial) se encontrava em um momento de bolha: era a época da bonança. Títulos rendiam retornos bem acima de sua media histórica, o mercado de capitais se desenvolvia, havia excesso de recursos, emprego, casas, etc.

Para começar a explicar o que aconteceu, precisaremos primeiro entender o que é uma hipoteca e como funciona o processo de securitização. Hipoteca, segundo Caio Mário da Silva Pereira" " "é o direito real de garantia de natureza civil, incidente em coisa imóvel do devedor ou de terceiro, sem transmissão da posse ao credor". A hipoteca é um direito real muito utilizado no mundo inteiro para que os donos de imóveis possam obter crédito, por ser procedimento em princípio seguro para os bancos: se o devedor não pagar a dívida, o banco tem o direito de penhorar o bem e vendê-lo, adimplindo assim a dívida.

Ainda nas palavras de Caio Mário:

\begin{abstract}
"Vencida e não paga a dívida, ou deixando o devedor de cumprir a obrigação, pode o credor promover a excussão da hipoteca mediante procedimento executório também denominado ação hipotecária, nome já consagrado desde a codificação de Justiniano: Item serviana et quasi serviana, quae etiam hipotecaria vocatur (Institutas, Liv. IV, Tít. $6, \S 7^{\circ}$ ).

Como procedimento de rito executório, referido no Código de Processo Civil (arts. 646 e segs.), obedece ao rito neste prescrito, iniciando-se com a citação para pagar, e imediata penhora do bem hipotecado. Percorridos os trâmites processuais, o imóvel é levado à hasta pública. Arrematado, o credor hipotecário paga-se pelo preço obtido, ou mediante adjudicação do próprio imóvel. Excedendo este ao valor da dívida, o remanescente pertence ao devedor hipotecário, ou destina-se a solver a segunda hipoteca, ou sobre ele instaura-se concurso de credores".
\end{abstract}

http://ssrn.com/abstract=1286903; GORTON, Gary B. Information, Liquidity and the (ongoing) panic of 2007. Disponível em: http://www.nber.org/papers/w14649; MAYER, Christpher J., PENCE, Karen. Subprime mortgages: what, where and to whom? Disponível em: http://www.nber.org/papers/w1408.

\footnotetext{
${ }^{5}$ PEREIRA, Caio Mário da Silva. Instituições de Direito Civil. Direitos Reais. $19^{\mathrm{a}}$ ed. Rio de Janeiro: Forense, 2007. p. 368.
} 
Já o termo securitização é palavra que vem do Inglês "securities", que significa valor mobiliário e que permite a integração entre o mercado de crédito e o mercado de valores mobiliários, aumentando assim sua eficiência, velocidade e competitividade. Charles Austin Stone e Anne Zissu $^{6}$, através de complexa explicação, definem o que seria o processo de securitização:

\begin{abstract}
"O processo ocorre da seguinte forma. Instituições financeiras (originadores) vendem conjuntos de hipotecas para entidades patrocinadas pelo governo (GSEs) - a Federal Home Loan Mortgage Corporation (FHLMC, ou Freddie Mac), a Federal National Mortgage Association (FNMA, ou Fannie Mae), ou a Government National Mortgage Association (GNMA, ou Ginnie Mae) - por dinheiro ou em troca de MBSs, ou vendem conjuntos de hipotecas por dinheiro para consumidores privados do tipo condutores. As GSEs e os condutores privados financiam suas compras dos conjuntos de hipotecas através de veículos chamados condutores para o investimento em hipotecas imobiliárias (REMICs) que então emitem posições múltiplas de curto, medio e longo prazo (chamadas camadas) de valores mobiliários. A estruturação dessas camadas, do tipo obrigações de hipotecas garantidas (CMOs), que são criadas para pagar diferentes taxas de juros dependendo de seu vencimento, depende da demanda para os diferentes elementos do conjunto de hipotecas. As entradas recebidas em função da emissão das CMOs são usadas para financiar a compra do conjunto de hipotecas do condutor. Os valores mobiliários lastrados em hipotecas recebidos em troca do conjunto de hipotecas são ou retidos pelo originador ou refinanciados através das REMICs. Existe também um mercado secundário ativo de hipotecas nos Estados Unidos. Os originadores vendem sua produção de conjuntos de hipotecas para os condutores que estocam tais empréstimos até que o conjunto seja grande o suficiente para ser securitizado. Condutores e originadores fazem hedge de suas exposições ao risco nos mercados de MBSs e de títulos do tesouro."
\end{abstract}

\footnotetext{
${ }^{6}$ STONE, Charles Austin; Zissu, Anne. The securities market handbook: structures and dynamics of mortgage - and asset - backed securities. Princeton: Bloomberg Press, 2005. p. 3 e 4. Tradução livre do original: "The process occurs as follows. Financial institutions (originators) sell pools of mortgages to government-sponsored enterprises (GSEs) - the Federal Home Loan Mortgage Corporation (FHLMC, or Freddie Mac), the Federal National Mortgage Association (FNMA, or Fannie Mae), or the Government National Mortgage Association (GNMA, or Ginnie Mae)-for cash or in exchange for MBSs, or they sell pools of mortgages for cash to private-conduit-type customers. The GSEs and private conduits finance their purchases of the mortgage pools via vehicles called real estate mortgage investment conduits (REMICs) that then issue multiple short-, medium-, and long-term positions (called tranches) of securities. The design of these tranches of collateralized mortgage obligations (CMOs), which are set up to pay different rates of interest depending on their maturity, depends on the demand for the various elements within the mortgage pool. Proceeds from the issues of CMOs are used to finance the purchase of the mortgage pool from the conduit. Mortgage-backed securities received in exchange for pools of mortgages are either retained by the originator or refinanced through REMICs. There is also an active forward market for mortgage loans in the United States. Originators sell their production of mortgage pools forward to conduits that warehouse the loans until the pool is large enough to be securitized. Conduits and originators hedge their risk exposures in the MBS and Treasury markets."
} 
Em outras palavras, securitizar é transformar um crédito (ou melhor definindo, um conjunto de créditos) em valor mobiliário. É um instrumento de mitigação do risco (ou mesmo de transferência) que faz com que quem passe a assumir o risco de inadimplência seja o eventual comprador dos títulos. No Brasil, a securitização de créditos imobiliários vem definida no art. $8^{\circ}$ da Lei ${ }^{\circ} 9.514 / 97$, que dispõe:

\footnotetext{
“Art. $8^{\circ}$ A securitização de créditos imobiliários é a operação pela qual tais créditos são expressamente vinculados à emissão de uma série de títulos de crédito, mediante Termo de Securitização de Créditos, lavrado por uma companhia securitizadora (...)"
}

Nesse sentido, e tendo em vista que o problema surgido nos Estados Unidos também surgiu da securitização de créditos imobiliários, vamos exemplificar como ocorre tal processo no mercado de hipotecas.

Suporemos que José da Silva possui uma casa no valor de US\$ 200.000,00 (duzentos mil dólares). Ele precisa de dinheiro para se financiar e portanto celebra um contrato de hipoteca com um banco que o empresta esses US\$200.000,00 (duzentos mil dólares) e presta, como garantia, sua própria casa. O banco, por sua vez, forma um conjunto de hipotecas e o vende para uma agência ou mesmo um outro banco que, então, emite títulos ("MBS" ou mortgage-backed security) lastreados nesse conjunto de hipotecas. Esses títulos são, em regra, vendidos no mercado (embora também possam ser usados para o pagamento aos vendedores de hipoteca). Uma vez vendidos no mercado, há a transferência do risco de inadimplemento. Assim, como o MBS é lastreado na hipoteca celebrada com José da Silva, se este não pagar sua dívida, os detentores dos MBSs ficarão sem o retorno esperado.

Essa situação, no entanto, não é necessariamente ruim se lembrarmos que esse processo gerava liquidez, agilidade e possibilidade de mitigação de riscos, ou melhor dizendo, possibilidade de que quem suporte o risco sejam entes com um perfil mais adequado para tal. Antes da crise e do processo de securitização, quem celebrava a hipoteca a mantia em seu poder, no sistema 
de originate-to-keep. Nesse sistema, temos presentes todos os incentivos para a correta análise do crédito: se o proprietário não pagar sua dívida, quem deixará de receber seu pagamento será o credor.

Já com o processo de securitização, passou-se a operar da seguinte maneira: Fannie Mae (Federal National Mortgage Association) e Freddie Mac (Federal Home Loan Mortgage Corporation), entidades patrocinadas pelo governo americano, compravam as hipotecas (ou os conjuntos de hipotecas) e elas mesmas emitiam as MBSs fornecendo garantia pelo seu retorno (mediante o pagamento de taxa de administração) e exigindo de seus vendedores, portanto, inúmeras diligências no sentido da correta avaliação do crédito (afinal, se avaliação fosse errônea, as entidades é que arcariam com o débito na qualidade de garantidoras). Mais uma vez, mantinham-se os incentivos para a devida análise da qualidade do crédito. Nesse sistema, se José da Silva não quitasse sua dívida, ainda assim o comprador do MBS receberia seu pagamento.

No entanto, mesmo ai, já vemos a possibilidade de risco moral (ou moral hazard) na emissão dessas MBSs. Ora, se não importa quantas hipotecas a agência comprar, o que ela receberá será a taxa de administração dessas MBSs, surge um incentivo para a geração do maior número de hipotecas possível, para lucrar mais (lembrando que essas entidades não eram mais governamentais, e sim privadas). Porém, como elas ainda terão que garantir eventual inadimplência, possivelmente ainda farão (ou exigirão que os vendedores de hipoteca façam) a análise de crédito com alguma diligência.

No entanto, bancos de investimento privados começaram a emitir MBSs. Se antes, Fannie Mae e Freddie Mac forneciam garantias no caso de inadimplemento por parte do devedor, esses bancos de investimento não o faziam. Assim, o mercado se encontrou inundado de títulos cuja única garantia era o esperado adimplemento por parte do proprietário. Os bancos de investimento passaram a dominar o mercado e as MBSs garantidas pelas agências se tornaram exceção. 
Como se pode perceber, estava-se diante de um excelente negócio do ponto de vista da lucratividade porém, um negócio que gerava um enorme risco moral na emissão, pois o lucro de agências e bancos de investimento passou a depender não mais da qualidade do crédito, e sim da quantidade de hipotecas geradas.

Porém, isso não foi suficiente. Tendo em vista as grandes oportunidades de lucro avistadas pelos bancos de investimento, eles passaram a criar SPVs (special purpose vehicle) ou, em nossos termos, sociedades de propósito específico ("SPE"), que passaram a atuar no mercado de securitização das MBSs e cujas eventuais perdas não eram refletidas nos balanços dos bancos.

A estratégia das SPEs se baseava em emitir títulos que ficaram conhecidos como collateralized debt obligation ("CDO”). Esses títulos eram divididos em três camadas, respectivamente: Sênior, Junior (ou mezzanine) e Equity. Cada um desses correspondia a uma diferente classe de risco, sendo o retorno proporcional a esse risco. A camada sênior seria então a primeira a receber retornos do conjunto de hipotecas, a Junior a segunda e a equity a última, sendo que cada uma dessas camadas só receberia seu pagamento se o retorno fosse suficiente para pagar as anteriores.

Vale lembrar que no caso dos bancos de investimento que emitiam CDOs através das SPEs, o que ocorria não era que eles estavam analisando mal o risco de crédito das hipotecas, mas sim confiando na precificação feita por terceiros (ou pelo próprio mercado) dessa geração de hipoteca. Vendiam papéis cuja precificação estava totalmente viezada, uma vez que eram lastreados em títulos que por sua vez eram lastreados em hipotecas cuja análise de crédito era falha, e a possibilidade de inadimplência altíssima (e dai decorre o termo subprime, que se refere à má qualidade das hipotecas).

Em princípio, para que o sistema funcionasse, era necessário que as camadas equity fossem detidas pelos próprios bancos de investimento, de 
modo que assim eles teriam incentivo para proceder a uma correta precificação dos títulos. No entanto, isso não ocorreu. Mais uma vez: como o risco era transferido aos compradores, o interesse das SPEs era em apenas vender o maior número de títulos possível.

Nesse ponto surge a inevitável pergunta: por que tais títulos eram comprados? Uma das respostas mais óbvias a essa pergunta é o fenômeno conhecido como Global Savings $\mathrm{Glut}^{7}$, colocado pela maioria dos autores como um dos motivos determinantes da crise e que pode ser entendido sob a lógica do agente superavitário e do agente deficitário. Ora, Nelson Eizirik já dizia, a respeito do mercado de capitais ${ }^{8}$ :

"Diversamente do que ocorre no mercado de crédito, no mercado de capitais, a mobilização da poupança é realizada diretamente entre a unidade econômica deficitária - a entidade emissora - e a unidade econômica superavitária - o investidor".

É claro que em se tratando de uma integração entre o mercado de crédito e o de capitais, as elaborações teóricas não se aplicam diretamente ao caso da securitização. Porém, no que diz respeito ao global savings glut, é exatamente essa a lógica que deve ser entendida.

Havia uma sobra de poupança nas economias em desenvolvimento e uma despoupança nas economias desenvolvidas. Assim, esse dinheiro que era excedente em um país em desenvolvimento precisava ser investido e os países desenvolvidos precisavam gerar atrativos para esse investimento. Esses títulos eram então, aparentemente, uma ótima oportunidade para ambos: atraíam o capital excedente em um mercado para aquele que estava dele necessitando 9 .

\footnotetext{
${ }^{7}$ John B. Taylor discorda que exista um global savings glut, argumentando que, empiricamente, não há evidências de um global savings glut, se utilizando de dados elaborados pelo FMI em 2005 (e, portanto, aparentemente ultrapassados).

${ }^{8}$ EIZIRIK, Nelson et al.. Mercado de capitais: regime jurídico. $2^{\mathrm{a}}$ ed. Rio de Janeiro: Renovar, 2008. p. 8 .

${ }^{9}$ Nas palavras de Martin Hellwig (HELLWIG, Martin. Systemic risk in the financial sector: an analysis of the subprime-mortgage financial crisis. Disponível em: http://www.coll.mpg.de/abst2008 43.html), no entanto, esse movimento teria se dado mais em função de haver sobra de capital do que da efetiva necessidade desse capital: “(...) the expansion of
} 
Existem ainda outras explicações para a compra desses ativos. Uma delas é o otimismo dos agentes de mercado e a confiança nas precificações fornecidas seja pelas agências seja pelo próprio mercado. Os agentes de mercado acreditavam estar protegidos através de hedge feitos com CDSs (credit default swaps $^{10}$ ) de eventuais perdas, sem levar em conta que as instituições que eram contraparte no hedge poderiam não honrar seus compromissos no caso de uma crise sistêmica.

Além disso, devem ser levadas em conta a soma de dois fatores que Martin Hellwig chama de peer pressure e market discipline.

Peer pressure ou se traduzirmos, a pressão dos pares, quer dizer nesse contexto o fato de ninguém questionar os investimentos em MBS CDOs e de não ser possível que tal questionamento fosse levantado. À época, quem questionasse os riscos de um investimento com tanta possibilidade de retorno, seria considerado um pária na organização. Market discipline, por sua vez, refere-se a pressão do mercado e dos próprios acionistas por retorno ao seu capital. Se a maioria das instituições financeiras estava com um lucro de $25 \%$ (vinte e cinco por cento) no período, os administradores das outras instituições eram obrigados a buscar lucros na mesma medida, para agradar ao mercado, aos seus acionistas e, em muitos casos, a seu próprio bolso (dado o fato de muitos administradores serem remunerados com base na valorização das ações de sua companhia ou banco). Assim, o administrador tinha que buscar altas taxas de retorno sem muitas vezes poder questionar se tais retornos valeriam a pena no médio e longo prazo, sem poder questionar o que essa promessa de blue sky poderia envolver.

Uma vez entendido esse processo, vamos à próxima e inevitável pergunta: o que deu errado?

subprime mortgage lending was driven by the supply of funds rather than the demand for fund in these markets. Increased mortgage lending was driven by investors seeking an outlet for their money".

${ }^{10}$ Através do contrato de CDS, uma parte faz pagamentos periódicos à outra parte para que garanta o inadimplemento de eventual obrigação que possui (no caso da ocorrência de um evento específico, acordado contratualmente, pagará um determinado montante à parte contratante). 
Primeiro devemos levar em conta que nessa estrutura de empréstimos, que ia desde o proprietário de imóvel comum até grandes bancos de investimentos, surgiram os problemas de incentivos. Como o ganho era exclusivamente baseado na quantidade de contratos gerados, a qualidade do crédito que era concedido foi colocada em segundo plano (não se procedendo, portanto, à correta análise do crédito e do risco de inadimplência de determinado devedor). Neste ponto, hipotecas eram concedidas sem o devido controle.

Dito isso, a conhecida preferência americana do consumo em detrimento da poupança (que os levava a hipotecar mais e mais vezes suas casas para obter o dinheiro líquido) associada às baixas taxas de juros encontradas no mercado americano pós-crise da Nasdaq e ao elevado nível de poupança do mundo em desenvolvimento (conforme explicado, em função do global savings glut), fez com que houvesse uma explosão de crédito de má qualidade.

Essa explosão de crédito gerou um aumento expressivo nos preços das casas, que fez com que novas famílias hipotecassem suas casas para alavancar ainda mais seu consumo. E assim, os preços das casas subiram mais uma vez. Essa espiral acabou causando a bolha do setor imobiliário. Com isso, cada vez mais casas foram construídas levando a uma explosão na construção imobiliária.

Todo esse bem estar no mercado imobiliário fez com que as famílias ficassem cada vez mais confortáveis em fazer hipotecas com as cláusulas de taxas de juros variáveis, as chamadas adjustable-rate mortgages, tendo em vista a confiança na manutenção da baixa taxa de juros por parte do governo. Se a taxa de juros viesse a subir (o que não era esperado até então), o risco de inadimplência aumentaria. Geralmente, quando um cliente não conseguia pagar sua hipoteca após o ajuste da taxa, ele a refinanciava, tornando ainda mais difícil o pagamento da primeira hipoteca. No ditado popular: "vendia-se o almoço para comprar o jantar". 
Outro motivo que contribuiu para a crise (e sua intensificação) foi o fato de a interferência estatal americana sempre ter sido intensa no sentido de manter os juros baixos, mantendo juros muitas vezes irreais. Enquanto os juros estavam baixos, não haviam maiores problemas. Eles começaram a surgir quando motivos macroeconômicos e a dificuldade do governo em manter as taxas de juros tão baixas fizeram com que, em 2004, elas começassem a subir sendo elevadas, em agosto de 2007, a aproximadamente $5,00 \%{ }^{11}$.

A esse propósito, cabe transcrever aqui a opinião de John B. Taylor:

“(...) ações governamentais e intervenções causaram, prolongaram e pioraram a crise financeira. Elas causaram por desviar dos precedentes e princípios históricos para a determinação das taxas de juros." 12

Com esse aumento repentino nos juros, cada vez mais proprietários passaram a não conseguir pagar suas hipotecas e a terem suas casas penhoradas e vendidas (através de processo de execução parecido com o que levantamos anteriormente, que é a razão de ser da hipoteca). Sendo assim, casas eram devolvidas ao mercado diariamente ao mesmo tempo que novas casas eram concluídas. Assim, os preços das casas começaram a despencar, e as pessoas pararam de pagar suas hipotecas, gerando mais penhoras, e alimentando novamente a espiral do mercado imobiliário: o número de casas à venda era muito maior do que o número de pessoas interessadas (e com disponibilidade financeira) em comprá-las e, pela simples lei de oferta e demanda, os preços das casas despencaram mais ainda.

Estava armado o cenário da crise que vemos hoje: com o colapso no mercado de hipotecas, aqueles inúmeros títulos que nelas eram lastreados e que estavam sem garantia alguma, ficaram sem retorno. Então, os agentes

\footnotetext{
${ }^{11}$ De acordo com o Board of Governors of the Federal Reserve System. Disponível em http://www.federalreserve.gov/releases/h15/.

${ }^{12}$ Do original: “ (...) government actions and interventions caused, prolonged and worsened the financial crisis. They caused it by deviating from historical precedents and principles for setting interest rates."
} 
de mercado começaram a questionar quanto realmente valiam aqueles títulos.

Dada a ausência de retorno, esses MBSs e CDOs passaram a valer muito menos do que o valor que se encontrava registrado no balanço das instituições financeiras, que foram obrigadas a fazer write-offs (ou writedowns) sucessivos em seus balanços de modo a refletir o real valor dos títulos (pois é isso que prevê a fair value accounting, ou contabilidade pelo valor justo, modelo que vigora nos Estados Unidos para a precificação de ativos). Isso aplica-se mesmo para aquelas instituições financeiras que criaram as SPEs, tendo em vista que, em última instância, eram responsáveis por sua solvência.

Diante do tamanho das instituições financeiras e do alto grau de interdependência entre elas, o colapso do sistema hipotecário levou a um colapso de uma e de outra instituição financeira, sucessivamente. Primeiro, o Bear Stearns, que já em 23 de junho de 2007 demonstrava problemas com seus hedge funds. Posteriormente, em 9 de agosto de 2007, o BNP Paribas demonstrava a dificuldade em avaliar seus ativos lastreados em hipotecas e, em 16 de outubro de 2007, ocorreu o primeiro de tantos write-downs que o seguiriam, no Citigroup. Desde então, seguiu-se a escalada para a maior crise desde a grande depressão.

Conforme demonstrado na tabela II, a transferência da tensão financeira é conseqüência da atual estrutura dos mercados mundiais. Aos poucos, a crise atingiu o resto do mundo, sendo inúmeros os registros de bancos e empresas em dificuldades, principalmente naqueles países cujo mercado estava em estreita conexão com o mercado americano ${ }^{13}$.

A pergunta que nos resta a responder, diante do exposto, é clara: onde estava o regulador? Para que ela possa ser respondida é necessário, contudo, que se discorra sobre as bases teóricas em que se estruturou a

\footnotetext{
${ }^{13}$ Por exemplo, conforme demonstrado no discurso de Ben. S. Bernanke, já mencionado, em 18 de setembro de 2008, a agência de hipotecas inglesa HBOS, que possuía patrimônio de mais de US\$ 1 trilhão, foi forçada a fundir com o Loyds TSB. Em 29 de setembro de 2008, os governos da
} 
regulação financeira no mundo, para que depois se possa analisar criticamente o que aconteceu com relação aos bancos de investimento.

Bélgica, Luxemburgo e Holanda nacionalizaram a Fortis, empresa bancária e de seguros que também possuía um patrimônio de grande vulto. 


\section{A regulação do mercado financeiro nos EUA e no Brasil}

Nesse capítulo serão abordados alguns aspectos relacionados aos sistemas teóricos referentes a estruturação da regulação financeira no mundo e a adoção de tais sistemas nos Estados Unidos e no Brasil. Para tanto, faz-se necessária uma pequena digressão a respeito do sistema financeiro e sua conceituação.

"O mercado financeiro e de capitais é aquele em que são negociados instrumentos financeiros ou em que se estabelecem relações de conteúdo financeiro visando, fundamental mas não exclusivamente, dois fins nem sempre concomitantes: a repartição de riscos e o financiamento das atividades econômicas."14

Nos centralizaremos, porém, na análise da segunda finalidade: a de financiamento das atividades econômicas. Em economias desenvolvidas, é essencial a existência de um sistema que aproxime o agente superavitário do agente deficitário.

Partindo desta compreensão, percebemos que há uma cisão entre mercado financeiro (em sentido estrito, compreendendo portanto o mercado de crédito ou bancário) e mercado de capitais, tendo em vista que ambos exercem essa aproximação entre agente superavitário e agente deficitário seguindo sua lógica própria.

Assim, nos vemos diante da diferença básica entre esses dois "submercados" ("sub-mercados" no sentido de mercados secundários que, globalmente, pertencem ao mercado financeiro em sentido lato):

\footnotetext{
"No mercado de crédito a transferência dos recursos financeiros é realizada de forma indireta. Os ativos financeiros são objeto de intermediação. As entidades especializadas, autorizadas a funcionar em tais mercados (as instituições financeiras), captam os ativos e os repassam, agindo, porém, em nome próprio. Quando uma instituição financeira recebe recursos provenientes de depósito ou aplicação e os empresta a um terceiro, age em nome próprio. Tanto o aplicador como o tomador mantêm relação direta com o banco, sendo irrelevante para o tomador de onde veio o dinheiro, e irrelevante para o aplicador o destino que ele tomou. Não há relação direta entre aplicador e tomador.
}

\footnotetext{
${ }^{14}$ YAZBEK, Otavio. Regulação do Mercado Financeiro e de Capitais. $2^{\mathrm{a}}$ reimpressão. Rio de Janeiro: Elsevier, 2007. p. 131.
} 
No mercado de valores mobiliários a transferência dos recursos financeiros é realizada de forma direta. Não existe intermediação efetiva (existe, quase sempre, a participação de um intermediário financeiro, mas tal intermediário não age em nome próprio). Quando uma companhia emite publicamente uma ação, apesar de ser obrigatória a participação de uma instituição financeira na operação, do ponto de vista jurídico, o subscritor adquire a ação diretamente da companhia. A relação jurídica entre o aplicador e o tomador é direta.

Em resumo, no mercado de valores mobiliários, as instituições especializadas tem uma função de aproximação, ao passo que, no mercado de crédito, tais instituições têm uma função de substituição." 15

A esses dois "sub-mercados", podemos adicionar como compondo o sistema financeiro o mercado de câmbio (em que se realiza, em última análise, a troca de moedas) e o mercado monetário (em que o governo realiza as atividades típicas de política econômica e em que são satisfeitas as necessidades de caixa das entidades).

Como se verá, tendo em vista a estrutura atual da economia em que o mercado como um todo necessita de crédito e de sua circulação para produzir riquezas e em que encontramos entidades com estruturas típicas de mercado de crédito atuando no mercado de capitais, podemos entender um dos importantes papéis que terá a regulação: compreender essa nova estrutura dos mercados para impedir que esse sistema como um todo entre em colapso, evitando efeitos negativos como os que vimos recentemente, descritos na primeira parte desse trabalho.

\subsection{Regulação}

Antes de iniciar qualquer debate sobre a regulação e sua estrutura, é necessário que se entenda o que é regular e quais são seus objetivos ${ }^{16}$.

Nelson Eizirik ${ }^{17}$, citando Johan Der $\operatorname{Hertog}^{18}$, diz não existir nem na literatura jurídica nem na literatura econômica uma definição uniforme do

\footnotetext{
${ }^{15}$ CHEDIAK, Julian Fonseca Peña. A reforma do mercado de valores mobiliários. In: Jorge Lobo (coord.). Reforma da Lei das Sociedades Anônimas. Rio de Janeiro: Forense, 2002. p. 531 e 532.

${ }^{16}$ Não se discutirá, neste trabalho em que se busca uma abordagem mais prática e ligada aos anseios atualmente existentes, as elaborações teóricas clássicas relativas a princípios da regulação, sua submissão ao direito administrativo e poderes das agências reguladoras. Sobre esses assunto, veja-se, por todos: SALOMÃO FILHO, Calixto. Regulação da atividade (princípios e fundamentos jurídicos). $2^{\mathrm{a}}$ ed. São Paulo: Malheiros, 2008 e SOUTO, Marcos Juruena Villela. Direito Administrativo Regulatório. $2^{\mathrm{a}}$ ed. Rio de Janeiro, São Paulo, Brasília e Rio Grande do Sul: Lúmen Juris, 2005.
} 
que devemos entender por "regulação", colocando que "podemos utilizar o termo como constituindo o emprego dos instrumentos legais necessários à implementação de objetivos de política econômica ou social”. Alexandre Santos de Aragão ${ }^{19}$, após discutir o conceito de regulação, conclui por entender a regulação estatal da economia como

\begin{abstract}
"o conjunto de medidas legislativas, administrativas e convencionais, abstratas ou concretas, pelas quais o Estado, de maneira restritiva da liberdade privada ou meramente indutiva, determina, controla, ou influencia o comportamento dos agentes econômicos, evitando que lesem os interesses sociais definidos no marco da Constituição e orientando-os em direções socialmente desejáveis."
\end{abstract}

No entanto, a definição de regulação e sua diferenciação de institutos afins é tema amplamente levantado pela doutrina. Alexandre Santos de Aragão $^{20}$, por exemplo, discorre sobre as diferenças entre regulação e regulamentação, colocando que regulamentação é definido por muitos como os mecanismos de caráter sancionatório e interventivo, enquanto regulação seriam o conjunto de medidas a orientar a atuação do particular. Porém, ele mesmo coloca a necessidade de vermos a regulação como o conjunto de regras tanto punitivas quanto indutivas, uma vez que hoje a atividade regulatória compreende ambas as "facetas" da regulação.

Além disso, alguns dizem que a regulação se referiria somente às atividades de regulação de ordem estatal, excluindo, por exemplo, aqueles mecanismos próprios do mercado ou emanados de outros entes (como a auto-regulação privada). Esse ponto de vista vem corroborado por Otávio

\footnotetext{
${ }^{17}$ EIZIRIK, Nelson et al.. Mercado de capitais: regime jurídico. 2a ed. Rio de Janeiro: Renovar, 2008. p. 13.

${ }^{18}$ HERTOG, Johan Den. General Theories of Regulation. In: Boude Wijn Bouckaert, Gerrit De Geest. In: Enciclopedia of Law and Economics, v. 3, Cheltenham, Edward Elgar Publishing Limited, 2001. Disponível em http://igitur-archive.library.uu.nl/law/2007-0221201358/hertog 99 generaltheoriesofregulation.pdf. Acesso em 29.09.2009.

${ }^{19}$ ARAGÃO, Älexandre dos Santos de. O Conceito Jurídico de Regulação da Economia. In: Revista de Direito Mercantil, $\mathrm{n}^{\circ}$ 122. Rio de Janeiro: Revista dos Tribunais. p. 39-47.

20 ARAGÃO, Alexandre dos Santos de. Regulação da Economia: Conceito e Características Contemporâneas. In: Revista de Direito da Associação dos Procuradores do Novo Estado do Rio de Janeiro, vol. XI - Direito da Regulação. Rio de Janeiro: Lúmen Juris, 2002. p. 6-11.
} 
Yazbek a respeito do nosso objeto de estudo: a regulação financeira. Segundo o autor ${ }^{21}$,

"a regulação financeira, porém, tende a ficar à parte neste discussão. Com efeito, ao se tratar de regulação das atividades bancárias, securitárias e de mercado de capitais, se está tratando de campos tipicamente explorados por agentes privados e que, desde sempre, foram objeto de regulamentação e de controle pelo Estado".

Neste estudo, usaremos do conceito amplo de regulação, compreendendo todas aquelas medidas que o Estado se utiliza para limitar ou orientar as atividades dos entes privados no que diz respeito ao acesso e atuação no mercado financeiro ${ }^{22}$. Vale ressaltar mais uma vez que foge do escopo deste trabalho a análise do poder punitivo ou das maneiras que possui o ente regulador de assegurar o cumprimento de suas normas. Os processos administrativos, as imposições de multa e todo o corolário desse sistema parajudicial não serão analisados.

Regular é, em outras palavras, limitar a atuação do particular em função do interesse público, tendo como objetivos precípuos (i) a proteção dos investidores; (ii) a eficiência do mercado; (iii) criação e manutenção de instituições confiáveis e competitivas; (iv) evitar a concentração do poder econômico; e (v) impedir a criação de situações de conflito de interesse. ${ }^{23}$

Tais objetivos podem ser alcançados pela regulação tanto através de edição de normas positivas quanto através de uma conduta negativa, vale dizer: o conceito de regulação já traz em si implícito a idéia de não regulação.

Desse modo, é importante notar que regular ou não regular é uma decisão política. Ao não limitar uma conduta, o legislador já está por tomar uma decisão regulatória: a opção política de, naquele caso, se omitir.

\footnotetext{
${ }^{21}$ YAZBEK, Otavio. Regulação do Mercado Financeiro e de Capitais. $2^{\mathrm{a}}$ reimpressão. Rio de Janeiro: Elsevier, 2007. p. 179.

${ }^{22}$ Excluiremos, como fazem os autores, a regulação da atividade econômica exercida diretamente pelo Estado, posto que não incluída no conceito de regulação. Cf., por todos, SALOMÃO FILHO, Calixto. Regulação da atividade (princípios e fundamentos jurídicos). $2^{\mathrm{a}}$ ed. São Paulo: Malheiros, 2008. p. 33-35.

${ }^{23}$ EIZIRIK, Nelson et al.. Mercado de capitais: regime jurídico. 2a ed. Rio de Janeiro: Renovar, 2008. p. 18.
} 
Regular mais, regular menos, a forma de regular. Todas essas decisões são tomadas de posições políticas que levam em conta a especificidade de cada contexto histórico, de cada realidade cultural na qual cada país está inserido.

Da análise dos objetivos da regulação podemos concluir que há uma interseção entre os diversos segmentos regulatórios, ou segmentos do mercado financeiro (mercado de capitais, mercado de crédito, regras concorrenciais, etc.). Assim, quando nos Estados Unidos os bancos de investimento que são grandes demais para falhar (no jargão muito utilizado, os too big to fail), falham, levando consigo o mercado financeiro inteiro, temos ai uma questão de concentração do poder econômico e de falha na confiabilidade e na competitividade de instituições financeiras. Quando é imposta a segregação espacial das atividades, obrigando que as atividades de venda e administração de carteira realizada em bancos múltiplos sejam segregadas, está-se tentando impedir o conflito de interesses de instituições financeiras.

Quando, no âmbito do mercado de capitais, existem normas de divulgação obrigatória de informações, o objetivo é proteger os investidores. Quando, no mesmo mercado, impede-se a manipulação de mercado, se quer buscar sua eficiência. Quando o CADE (Conselho Administrativo de Defesa Econômica), por sua vez, impede a fusão entre duas empresas de que resultaria um controle do mercado, busca-se proteger o abuso do poder econômico. O que podemos perceber é que na prática, nenhuma dessas atitudes se apresenta isoladamente: são todas um conjunto de normas que visam atingir os objetivos já citados.

Nesse contexto, surge a distinção entre duas funções regulatórias: regulação prudencial e regulação de $\operatorname{condutas}^{24}$. A regulação prudencial é aquela que impõe normas mínimas de liquidez, alavancagem, exposição ao

\footnotetext{
${ }^{24}$ Otávio Yazbek adiciona a essas duas funções a função de regulação sistêmica, que será tratada neste trabalho como parte integrante da regulação prudencial. Em: YAZBEK, Otavio. Regulação do Mercado Financeiro e de Capitais. $2^{\text {a }}$ reimpressão. Rio de Janeiro: Elsevier, 2007. p. 190.
} 
risco, etc. - é a típica regulação bancária. É uma norma silenciosa cuja função é garantir a segurança do sistema (por isso é conhecida, em inglês, pelo termo safety and soundness supervision function). Sua natureza silenciosa se faz perceber pela própria função a que se destina: o regulador não ganharia nada alardeando possíveis infrações para que elas fossem resolvidas, pois assim estaria prejudicando sua própria função de garantir a segurança do sistema (por gerar dúvidas que levariam à sua instabilidade).

Já a regulação de condutas, por sua vez, é aquela típica da regulação de mercado de capitais: exige informações e é barulhenta, alardeante. É uma regulação cuja função é regular a maneira de conduzir os negócios e cuja necessidade de alarde é clara: uma vez constatada irregularidade, nesse caso, é necessário que todos os agentes de mercado estejam cientes de tal irregularidade para que isso possa influenciar sua tomada de decisões.

\subsection{A estrutura da supervisão financeira}

Quanto à supervisão financeira, temos seus objetivos melhores detalhados como sendo: (i) segurança e estabilidade das instituições financeiras; (ii) mitigação do risco sistêmico; (iii) correição e eficiência dos mercados; e (iv) proteção dos consumidores e investidores ${ }^{25}$. Ora, se compararmos com os objetivos levantados por Nelson Eizirik, perceberemos que na realidade se tratam dos mesmos objetivos, revestidos de roupagem diferente.

A esses objetivos o Group of Thirty adiciona a busca pelo mínimo fardo regulatório através de eficiência e gerenciamento de custos.

A segurança e estabilidade das instituições financeiras é um objetivo cujo atingimento passa por uma combinação de regras e exames de supervisão prudencial. Tradicionalmente, se busca atingir tal objetivo através da persuasão, e não através da imposição de multas e penalidades, e por isso mesmo ele é feito através de normas prudenciais.

\footnotetext{
${ }^{25}$ Vários. The structure of financial supervision: approaches and challenges in a global marketplace. Publicação do The Group of Thirty. Disponível em: http://www.group30.org/pubs/GRP30_FRS_ExecSumm.pdf. Acesso em 27.03.2009.
} 
Supervisionar o sistema financeiro como um todo, mitigando o risco sistêmico, é apontado como o objetivo mais indiscutível da regulação, porém o mais desafiador. Significa, em geral, proteger o funcionamento do sistema financeiro causado pela quebra de um ou mais de seus componentes chaves. É, mais uma vez, o too big to fail, que vimos nos Estados Unidos. Otávio Yazbek, ao discorrer sobre a regulação sistêmica, explica a lógica da regulação financeira sob esse ponto de vista ${ }^{26}$ :

\footnotetext{
"A regulação sistêmica, por sua vez, é voltada para a proteção do sistema financeiro como um todo e, de forma reflexa, para a proteção das atividades não financeiras dele dependentes, adotando um mecanismo de 'conformação' do mercado. Assim, tal regulação envolve a criação de 'redes de proteção' ou de mecanismos de 'blindagem' destinados a permitir a administração das crises ou a resolução de problemas, impedindo o seu alastramento.”
}

A correição e eficiência dos mercados está refletida na precificação eficiente. Para obtê-la, surgem as proibições ao insider trading e as normas de disclosure, exigindo a transparência das informações no mercado. Assim, presume-se que os ativos negociados estarão precificados da maneira correta, através da tomada de decisões ótimas pelos participantes do mercado que, idealmente, possuirão todas as informações sobre o ativo de maneira clara e completa.

Nesse ponto vale ressaltar o antagonismo muitas vezes existente entre as normas de transparência e as normas que buscam manter a segurança e estabilidade das instituições financeiras. Vemos que enquanto um investidor espera que o mercado precifique os ativos de maneira correta através da obtenção de informações, para uma instituição financeira em dificuldade, divulgar tais informações pode piorar sua situação e comprometer sua estabilidade. É ai que surgem as diferentes respostas dadas por diferentes reguladores em vários países.

Com relação a proteção dos consumidores e investidores, estamos diante das normas de conduta, que visam garantir o tratamento justo e altos

\footnotetext{
${ }^{26}$ YAZBEK, Otavio. Regulação do Mercado Financeiro e de Capitais. $2^{\mathrm{a}}$ reimpressão. Rio de Janeiro: Elsevier, 2007. p. 190.
} 
padrões de conduta pelos intermediários. Essa é a regulação típica do mercado de capitais, embora hoje já esteja se expandindo para o mercado bancário. Trata-se de normas sobre, por exemplo, conflitos de interesse, restrições a publicidade e padrões de adequação.

Tendo em vista serem esses os objetivos comuns delineados qualquer que seja a estrutura de regulação que se adote, podemos adentrar na análise das estruturas da supervisão financeira em si, lembrando que não existe nenhum exemplo puro de algum dos quatro modelos no mundo e que nenhum modelo é o ideal para todas as realidades ${ }^{27}$.

Cada país deve escolher seu modelo ou adotar um modelo misto tendo em vista as especificidades de sua economia, desenvolvimento histórico, regras e estruturas administrativas internas, etc. Existem no mundo quatro modelos mais utilizados para a organização da regulação financeira: (a) o modelo institucional; (b) o modelo funcional; (c) o modelo integrado ou de um único regulador; e (d) o modelo da regulação por objetivos ou de twin peaks.

\subsubsection{O modelo institucional}

O modelo institucional é uma das maneiras clássicas de regulação da atividade econômica. Consiste em uma divisão das atividades regulatórias tendo em vista o tipo legal da entidade regulada, cada tipo de intermediário financeiro, sem levar em conta as atividades que desempenham. Assim, cada tipo de entidade (bancos, seguradoras, corretoras de valores mobiliários) estarão sujeitos a regulação de uma agência especializada na regulação daquela atividade econômica, que a regulará tanto pela perspectiva prudencial quanto pela perspectiva das normas de conduta.

\footnotetext{
${ }^{27}$ Nesse sentido, James R. Barth e outros dizem que a estrutura adotada para a regulação não parece afetar diretamente a eficiência das instituições. Cf.: BARTH, James R., NOLEE, Daniel E., PHUMIWASANA, Triphon, e YAGO, Glenn. A cross-country analisis of the bank supervisory framework and bank performance. Disponível em http://papers.ssrn.com/sol3/papers.cfm?abstract_id=325061. Acesso em 14.10.2009.
} 
Os problemas apontados pelo Group of Thirty $^{28}$ com relação a esse modelo regulatório são inúmeros. Primeiramente, tendo em vista o desenvolvimento dos serviços financeiros, não há mais essa divisão de produtos que cada entidade financeira oferece. Ao contrário, hoje as entidades oferecem os mais variados tipos de serviços financeiros sem mudar sua classificação ou tipo legal.

Uma vez interligados, teríamos uma interseção entre vários entes reguladores no que diz respeito aos assuntos regulados, podendo levar ao fato de que diferentes agências possuíssem diferentes regras para a mesma atividade. Nas palavras do Group of Thirty:

"Tendo em vista que a mesma atividade econômica, ou atividade econômica similar, pode ser conduzida por entidades que estão legalmente autorizadas e são supervisionadas como bancos, seguradoras, ou empresas ofertantes de valores mobiliários, os diferentes reguladores institucionais podem regular a atividade diferentemente uns dos outros." 29

A esse problema, Otávio Yazbek adiciona os movimentos de conglomeração, colocando que nesse caso também a estrutura institucional se mostra ineficiente, mas dessa vez pela dificuldade em analisar o "todo" da instituição.

Assim sendo, o modelo institucional seria um dos mais difíceis de se colocar em prática sem, no mínimo, uma inserção de alguns elementos do modelo funcional. Além disso, a ausência de um regulador com uma visão global dos negócios de uma entidade ou do mercado como um todo dificulta a regulação do risco sistêmico, fator de muita relevância nos dias atuais (que, conforme já mencionado, pode levar ao colapso do sistema como um todo).

\footnotetext{
${ }^{28}$ Ob. Cit.

${ }^{29}$ Do original: "Because the same or economically similar activity may be conducted by entities that are legally autorized and overseen as banks, insurance companies, or securities firms, the separate institutional regulators may regulate the activity differently". Em: Vários. The structure of financial supervision: approaches and challenges in a global marketplace. Publicação do The Group of Thirty. Disponível em: http://www.group30.org/pubs/GRP30_FRS_ExecSumm.pdf. Acesso em 27.03.2009.
} 


\subsubsection{O modelo funcional}

Já no modelo funcional a supervisão é fixada em função do tipo de atividade desenvolvida pela entidade a ser supervisionada, sem observância de seu tipo legal. Assim como no modelo institucional, essa supervisão é desenvolvida tanto do ponto de vista prudencial como no que diz respeito a normas de conduta. A esse respeito, Otávio Yazbek $^{30}$ diz que o sistema funcional descuida-se da dimensão prudencial, na medida em que há uma análise não da instituição em si, mas sim de suas atividades.

Nesse modelo teremos, a título de ilustração, uma agência especializada na supervisão das atividades de seguro, outra das ofertas de valores mobiliários, outra das atividades bancárias, e assim sucessivamente.

Em teoria, essa divisão é excelente pois permite a especialização da agência de seu pessoal e a consistência das normas com relação aquele tipo de atividade, permitindo que todas as normas emanem de uma só agência (em contraposição a várias agências regulando a mesma atividade como no caso do modelo institucional).

Das falhas apontadas pelo Group of Thirty ${ }^{31}$ com relação a esse modelo, selecionamos algumas. A mais importante delas seria a dificuldade em definir que tipo de produto estaria sujeito a supervisão de que agência, tendo em vista a enorme inovação financeira que enfrentamos. Essa "disputa" entre as agências pode levar a que o produto fique desregulado ou que, diante de uma indefinição por parte das agências com relação a quem regula determinado produto, os agentes o ofertem em outro mercado com regras mais claras.

Somado a isto temos o fato de que uma só entidade estará sujeita a supervisão de inúmeros reguladores, o que gera custos. Este fato faz ainda com que, em alguns momentos, se tenha um duplo grau de supervisão, que mais uma vez eleva os custos da atividade empresarial. Além disso, as entidades reguladas ficam sujeitas a decisões díspares por parte dos

\footnotetext{
${ }^{30} \mathrm{Ob}$. Cit.

${ }^{31}$ Ibid.
} 
reguladores que, eventualmente, venham a supervisionas uma mesma atividade. Assim, é essencial na adoção desse modelo que haja forte coordenação e interação entre as agências de modo a delimitar precisamente o que é ou não de competência de uma ou de outra e mais: de modo a evitar que aspectos da atividade financeira fiquem totalmente desregulados (como aconteceu com os bancos de investimento nos Estados Unidos, por exemplo).

Assim como no modelo institucional, no modelo funcional também se tem os desafios relacionados a falta de visão global de uma entidade ou do mercado financeiro como um todo: o risco sistêmico, mais uma vez, é de difícil supervisão.

Sob esse aspecto, muito ilustrativa é a conclusão de Otávio Yazbek:

"Em sistemas mais simples, em que as instituições desenvolvem as atividades de forma especializada (o que se caracteriza como narrow banking), a distinção entre regulação institucional e regulação funcional é pouco relevante, uma vez que intermediários e mercados estão necessariamente vinculados. Boa parte dos regimes existentes ao redor do mundo se baseia, na prática, em combinações entre esses dois padrões, com o estabelecimento de mecanismos de regulação próprios para alguns intermediários e também para atividades específicas. Os problemas começam, porém, quando da ocorrência daqueles fenômenos globais acima descritos [entre eles, o risco sistêmico]" (grifou-se)

\subsubsection{O modelo integrado}

O modelo integrado também pode ser chamado de modelo do único regulador: existe um único regulador para a supervisão prudencial e de condutas de todo o sistema financeiro.

As vantagens, se comparado com o modelo institucional ou funcional são claras: existindo um único regulador, em princípio, não estaríamos diante do problema de conflitos de normas sobre uma mesma matéria, nem sobre uma disputa por jurisdição entre diferentes agências, que poderia levar a uma não regulação da atividade (analogamente, como o que ocorreria com um conflito negativo de competência sem que houvesse algum tribunal para saná-la). 
Por possuir uma visão ampla, abrangente, do sistema, as respostas do regulador seria mais ágil, e este poderia regular eficientemente o risco sistêmico. Para as empresas, um único regulador também seria positivo, pois reduziria os custos de compliance, trazendo maior segurança jurídica para sua atuação.

Por outro lado, um único regulador também representa uma única supervisão: se esta supervisão falha, não há uma revisão (como se dá, ainda analogamente, no duplo grau de jurisdição). Assim, conforme bem colocado pelo Group of Thirty: "com o monopólio de um único regulador, não existe sistema de checks and balances." 32 Soma-se a isso uma conclusão óbvia: embora não segmentada em diferentes agências reguladoras, o único regulador, para que consiga supervisionar toda a atividade financeira, terá que se segmentar. Ai, estar-se-ia transportando para o âmbito interno do regulador todos os assuntos relacionados à coordenação, interação e superposição de normas. Ademais, um único regulador pode trazer consigo todas as ineficiências relacionadas à falta de competição.

\subsubsection{O modelo de twin peaks}

O modelo de twin peaks por sua vez, refere-se a regulação por objetivo: separa-se a função regulatória entre dois reguladores, um que realizará a regulação prudencial e outro a quem ficará designada a função de regulação de condutas. Estaríamos aqui diante de um modelo que se dirige a falhas de mercado específicas.

Nas palavras do Group of Thirty:

"o modelo de Twin Peaks de supervisão financeira é projetado para possuir todos os benefícios e eficiências do modelo integrado e ao mesmo tempo lidar com os

\footnotetext{
${ }^{32}$ Do original: "with a single monolithic regulator, no such sistem of checks and balances exists". Em: Vários. The structure of financial supervision: approaches and challenges in a global marketplace. Publicação do The Group of Thirty. Disponível em: http://www.group30.org/pubs/GRP30_FRS_ExecSumm.pdf. Acesso em 27.03.2009.
} 
conflitos inerentes entre os objetivos da regulação prudencial e da regulação de condutas" ${ }^{\prime 3}$.

Quanto ao modelo de twin peaks, haveriam mais vantagens do que desvantagens. Ele permitiria um equilíbrio entre a proteção ao consumidor através da regulação de condutas e a integridade do sistema financeiro através da regulação prudencial (não obstante serem mantidas tensões entre as agências quando necessário o sopesamento entre as duas funções).

Essa separação entre regulador prudencial e regulador de condutas permitiria uma melhor especialização dos técnicos da agência além de minimizar, em muito, os conflitos entre elas, pois cada uma estaria regulando as atividades a partir de um ponto de vista, com um objetivo específico.

Ainda nesse modelo, contudo, podem ser apontadas falhas: possibilidade de duplicação de esforços, criação de áreas não reguladas - o que será discutido no capítulo 3 desta monografia - ou mesmo o tratamento excessivamente uniformizado de mercados distintos ${ }^{34}$.

Após discutir sobre os aspectos teóricos relacionados a estrutura da supervisão financeira, é imperativo que se faça uma análise de sua aplicação concreta em cada um dos países. Neste estudo, contudo, nos focaremos na análise da estrutura americana, por ser lá o foco da crise e da estrutura pátria, por motivos óbvios.

\subsection{A estrutura para a supervisão financeira nos Estados Unidos}

A estrutura para a regulação financeira nos Estados Unidos pode ser classificada como funcional com traços de regulação integrada (que será aqui chamada de consolidada). Isso pois embora funcional, existe a

\footnotetext{
${ }^{33}$ Do original: "The Twin Peaks Approach to financial supervision is designed to garner all the benefits and efficiencies of the Integrated Approach, while at the same time addressing the inherent conflicts between the objetives of safety and soudness regulation and consumer protection and transparency". Em: Vários. The structure of financial supervision: approaches and challenges in a global marketplace. Publicação do The Group of Thirty. Disponível em: http://www.group30.org/pubs/GRP30_FRS_ExecSumm.pdf. Acesso em 27.03.2009.

${ }^{34}$ YAZBEK, Otavio. Regulação do Mercado Financeiro e de Capitais. $2^{\mathrm{a}}$ reimpressão. Rio de Janeiro: Elsevier, 2007. p. 195.
} 
supervisão "guarda-chuva" ou complementar feita por algumas entidades. É uma estrutura extremamente complexa e única, em que há quase sempre a dupla supervisão - estatal e federal - tendo em vista a natureza de federação desse país e seus movimentos históricos. A estrutura atual da regulação americana foi sendo moldada de acordo com os movimentos históricos e políticos, e hoje é foco de grande discussão e propostas de revisão ${ }^{35}$.

Atualmente, o sistema americano é composto dos seguintes órgãos na esfera federal: President's Working Group on Financial Markets ("PWG"), Federal Reserve Board ("FED"), Office of the Comptroller of the Currency ("OCC"), Office of Thrift Supervision (“OTS"), Federal Deposit Insurance Corporation ("FDIC"), National Credit Union Association ("NCUA"), Securities and Exchange Comission ("SEC") e Commodity Futures Trading Comission (“CFTC") e, complementariamente, o Federal Financial Institutions Examination Council ("FFIEC"), distribuídos conforme tabela abaixo:

\section{Tabela III - A Estrutura da Regulação Financeira Americana}

Fonte: Group of Thirty. Vários. The structure of financial supervision: approaches and challenges in a global marketplace. Publicação do The Group of Thirty. Disponível em: http://www.group30.org/pubs/GRP30 FRS ExecSumm.pdf. Acesso em 27.03.2009.

\footnotetext{
${ }^{35}$ Sendo a mais importante delas a Blueprint emitida pelo departamento do tesouro americano com indicações para uma possível reforma da regulação financeira. Ver: THE DEPARTMENT OF THE TREASURY. Blueprint for a Modernized Financial Regulatory Structure. Disponível em: http://www.treas.gov/press/releases/reports/Blueprint.pdf. Acesso em 29.10.2009.
} 


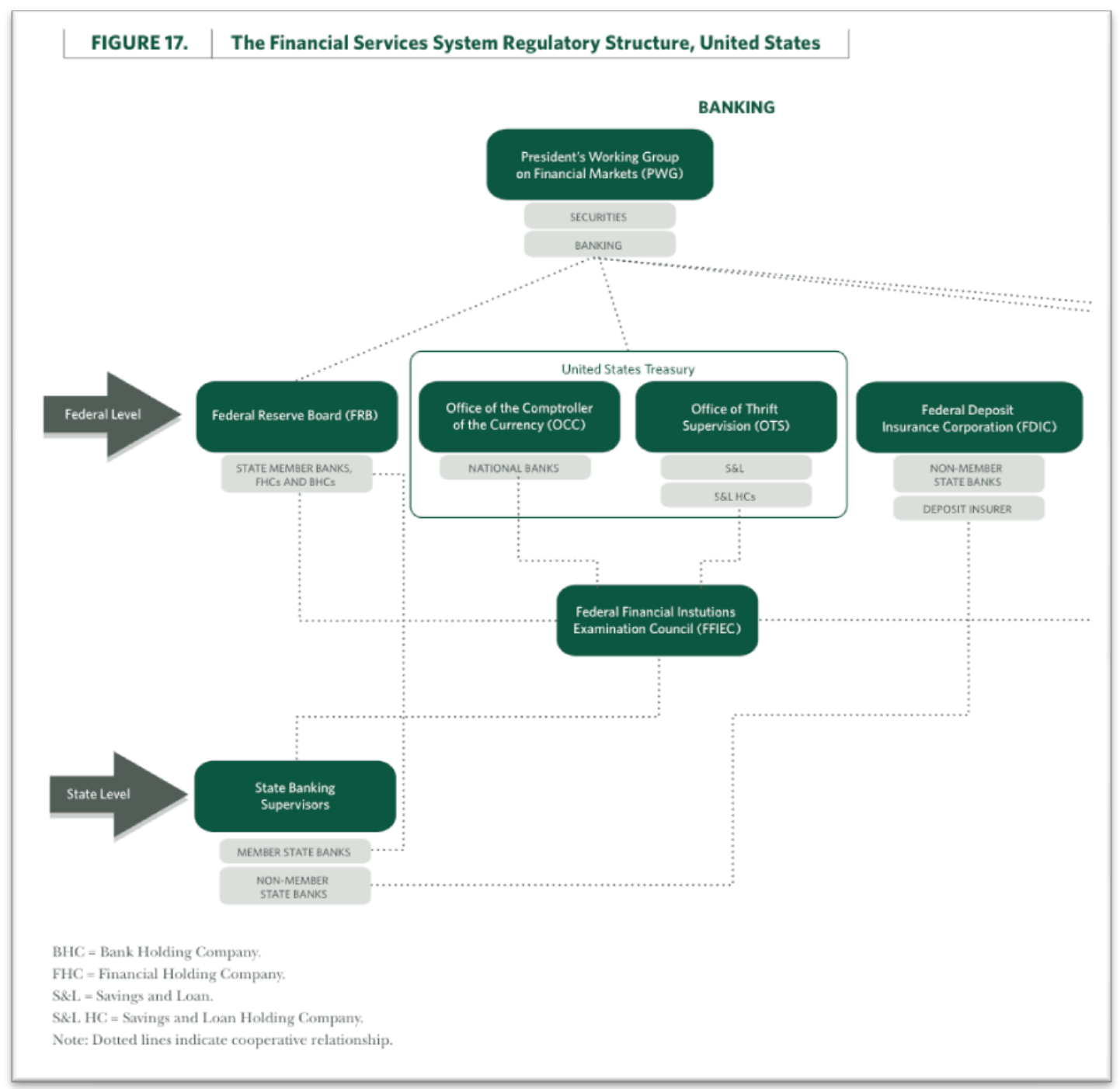


O FED, estabelecido em Nova Iorque, e os 12 (doze) Federal Reserve Banks distritais compõem o que podemos chamar de Federal Reserve System (criado pelo National Bank Act de 1913). O Federal Reserve System desenvolve inúmeras atividades sistêmicas, incluindo, com relação à supervisão financeira, a supervisão e regulação de todos os bancos estaduais membros, holdings bancárias (as Bank Holding Companies) e a função de garantidor dos depósitos de cada um de seus estados-membros.

O FED é uma agência governamental, composta de 7 (sete) membros indicados pelo presidente dos Estados Unidos e confirmados pelo Senado. Já os Federal Reserve Banks distritais são compostos por uma diretoria de 
por nove diretores não integrantes do FED, buscando refletir a paridade e a representação dos interesses dos diferentes ramos da economia.

Ao FED compete a supervisão e regulação financeira dos bancos estaduais através do estabelecimento de políticas e normativos, enquanto a supervisão e o acompanhamento é feito pelos Federal Reserve Banks distritais.

O OCC, por sua vez, é um órgão do Departamento do Tesouro americano que, segmentado em diversos escritórios estatais, estabelece políticas e normativos relacionados aos bancos federais e os supervisiona.

Já o OTS, também órgão do Departamento do Tesouro americano, supervisiona as chamadas Thrift Institutions e suas holdings, que podem ser por nós entendidas como as famosas Savings and Loan Association, ou seja, associações depositárias que se especializam em oferecer hipotecas, empréstimos, etc.

À FDIC cabe supervisionar os bancos e instituições de depósito estatais não afiliados ao Federal Reserve System (mais do que a metade das instituições que compõem o sistema bancário americano), além de possuir competência residual para examinar os outros bancos segurados e Thrift Institutions. O FDIC é garantidor de depósitos feitos nessas instituições sob a forma de poupança, conta-corrente, ou outras contas poupanças. Por outro lado, ela não garante valores mobiliários, fundos mútuos, ou investimentos similares que os bancos e as thrift institutions podem oferecer.

A NCUA foi formada para supervisionar e custear as Credit Unions federais. Ao mesmo tempo, foi criado um sistema de segurança de depósitos para os depósitos feitos nas Credit Unions.

A SEC, por sua vez, é o regulador do mercado de capitais. A ela cabe: (i) proteger investidores; (ii) manter a eficiência, organização e equilíbrio do mercado; e (iii) facilitar a acumulação de capital $^{36}$. Para tal, ela utiliza primariamente de regras de transparência para manter a negociação equilibrada e inibir fraudes.

\footnotetext{
${ }^{36}$ Para mais informações, ver: http://www.sec.gov/about/whatwedo.shtml.
} 
A SEC supervisiona aqueles que participam do mercado de capitais, dentre eles as bolsas de valores mobiliários, as corretoras e distribuidoras de valores mobiliários, os consultores de investimentos e os fundos mútuos.

Por último, a CFTC, reguladora do mercado de futuros e opções, tem como missão "proteger os usuários do mercado e o público da fraude, manipulação e práticas abusivas relacionadas a venda de commodities, futuros e opções, e incentivar a amplitude, competitividade e higidez financeira dos mercados de futuros e opções",37.

Conforme já dito, devemos levar em conta que nos Estados Unidos inúmeros seguimentos do mercado financeiro são regulados por reguladores estatais. Assim, existem os reguladores estatais bancários, de valores mobiliários e, principalmente, os de seguros. Dizemos principalmente pois nos Estados Unidos o mercado de seguros é quase que exclusivamente regulado e supervisionado por reguladores estatais.

Complementariamente ao sistema estatal para a regulação, nos Estados Unidos existem inúmeras instituições privadas que regulam o mercado financeiro através da auto-regulação. Nesse caso, se trata de autoregulação autorizada, posto que a SEC delega algumas de suas funções a essas entidades e as supervisiona. Isso acontece tanto no caso da negociação com valores mobiliários quanto com futuros (a competência para supervisionar as entidades que auto-regulam o mercado de seguros é da SEC e não da CFTC) ${ }^{38}$.

A título exemplificativo, as principais leis americanas sobre a regulação financeira são ${ }^{39}$ :

(i) National Bank Act de 1863: criou os bancos custeados pelo Governo, que seriam supervisionados pelo OCC;

\footnotetext{
${ }^{37}$ Cf. sítio da CFTC, em: http://www.cftc.gov/aboutthecftc/index.htm.

${ }^{38}$ Foge do escopo desse trabalho a análise sobre a auto-regulação. Sobre essas entidades e suas funções, ver: Vários. The structure of financial supervision: approaches and challenges in a global marketplace. Publicação do The Group of Thirty. Disponível em: http://www.group30.org/pubs/GRP30_FRS_ExecSumm.pdf. Acesso em 27.03.2009.

${ }^{39}$ Cf. Vários. The structure of financial supervision: approaches and challenges in a global marketplace. Publicação do The Group of Thirty. Disponível em: http://www.group30.org/pubs/GRP30_FRS_ExecSumm.pdf. Acesso em 27.03.2009.
} 
(ii) Federal Reserve Act de 1913: criou o Federal Reserve System e estabeleceu os poderes do FED;

(iii) Banking Act de 1933 ou Glass Steagall Act: criou a FDIC e o sistema de garantia de depósitos federal, criou procedimentos para lidar com bancos insolventes, autorizou o poder de punir dos reguladores bancários, cuidou de abusos nas atividades de underwriting bancárias, estabeleceu a segregação entre as atividades bancárias;

(iv) Securities Act de 1933: normas de transparência e combate à fraude;

(v) Securities Exchange Act de 1934: criou a SEC e formou a base do sistema de regulação financeira ao definir sua competência sobre ;

(vi) Home Owners' Loan Act de 1934: inúmeros incentivos ao mercado de hipoteca americano. Aditado posteriormente, concedeu ao OTS a competência para supervisionar as atividades de hipotecas feitas por Savings and Loan Associations e suas holdings;

(vii) Federal Credit Union Act de 1934: autorizou a criação de credit unions custeadas pela união federal em todos os estados. Em 1970, a NCUA foi criada para supervisionar essas atividades;

(viii) Commodity Exchange Act de 1936: estendeu a regulação federal a uma série de commodities que não só o grão e criou a entidade que posteriormente viria a ser a CFTC, quando da alteração da lei de 1974,que alargou sua competência alargada para todas as commodities;

(ix) Trust Indenture Act de 1939: especifica que títulos, debêntures e notas oferecidas ao público somente podem ser ofertados mediante a assinatura de um acordo, o trust indenture, nos termos dessa lei;

(x) Investment Company Act de 1940: regula a organização de empresas e fundos mútuos cujo objeto primário é investir, reinvestir e negociar valores mobiliários, e cujos próprios valores são ofertados ao público. Emana normas relacionadas às atividades do fundo; 
(xi) Investment Company Act de 1940: regula os consultores de investimentos e impõe que aqueles com específicas características se registrem na SEC;

(xii) McCarran-Ferguson Act de 1945: permitiu que os estados continuassem regulando o mercado de seguros;

(xiii) Administrative Procedure Act de 1946: estabelece a base para a responsabilidade de agências reguladoras do mercado financeiro;

(xiv) Federal Deposit Insurance Act de 1950: regula o FDIC e o seguro de depósitos, procedimentos para a administração de bancos insolventes, aumenta o poder de punir dos bancos, dentre outros;

(xv) Bank Holding Company Act de 1956: define o conceito de holding bancária, controla sua expansão e limita as atividades não bancárias em que elas podem se engajar;

(xvi) Federal Deposit Insurance Corporation Improvement Act de 1991: promulgada durante a crise das savings and loan institutions, introduz um esquema formal para as ações corretivas imediatas e requer a solução menos custosa para as instituições depositárias em crise;

(xvii) Gramm-Leach-Bliley Act de 1999: estabelece uma série de regras com relação aos conglomerados bancários e outros fornecedores de serviços financeiros, tais como as companhias de seguro e empresas emissoras de valores mobiliários, permitindo que atuem nos mais diversos segmentos de mercado, acabando com a segmentação bancária. Estabelece que o FED será o supervisor residual das holdings bancárias e que suas afiliadas ou subsidiárias não bancárias serão reguladas por seus reguladores funcionais primários; e

(xviii) Sarbaynes-Oxley Act de 2002: inúmeras reformas visando aumentar a responsabilidade corporativa, aumentar a transparência das empresas, e combater fraudes comerciais e contábeis. Cria o Public Company Accounting Oversight Board (PCAOB). 


\subsection{A estrutura para a supervisão financeira no Brasil}

Deixando de lado a discussão sobre a natureza das agências reguladoras, que em sua maioria hoje já se constituem como autarquias especiais, partiremos para uma análise das agências e órgãos que compõem o sistema de supervisão financeira brasileiro.

O sistema de regulação brasileiro, embora visto por muitos leigos como de regulação por objetivos ou de twin peaks, devido ao destaque dado às funções exercidas pela Comissão de Valores Mobiliários ("CVM") e pelo Banco Central do Brasil ("BCB"), na realidade é estruturado com base em um modelo funcional com aspectos institucionais. Assim é que possuímos inúmeros órgãos para a regulação financeira de que muitos nunca ouviram falar, mas que seguem essa lógica para a regulação.

Um dos importantes fatores que deve ser levado em conta na estrutura brasileira é a permissão da existência de bancos múltiplos que embora em primeira análise tenha sido considerada ruim por muitos, em última análise fez com que todas as atividades bancárias se mantivessem sob a supervisão do $\mathrm{BCB}$, impedindo, ao menos teoricamente, que o que aconteceu nos Estados Unidos viesse a ocorrer aqui (o que será abordado no capítulo 3).

Ao BCB, autarquia federal criada pela Lei do Sistema Financeiro Nacional (Lei $\mathrm{n}^{\circ}$ 4.595/64) compete, de maneira geral, supervisionar o sistema financeiro. Para tal, a ele incumbe executar as políticas, normas e decisões do Conselho Monetário Nacional (“CMN”), órgão também criado pela referida lei.

Dentre as atribuições conferidas pela Lei $\mathrm{n}^{\circ} 4.595 / 64$ ao BCB, podemos destacar:

\footnotetext{
"privativamente, (i) exercer a fiscalização das instituições financeiras e aplicar as penalidades previstas; (ii) conceder autorização às instituições financeiras, a fim de que possam funcionar no país, ser transformadas, fundidas, incorporadas ou encampadas, praticar operações de câmbio e crédito, entre outras; (iii) estabelecer condições para a posse para o exercício de quaisquer cargos de administração de instituições financeiras privadas; (iv) determinar que as matrizes das instituições financeiras registrem os cadastros das firmas que operam com suas agências há
} 
mais de um ano; e não privativamente, (v) exercer permanentemente vigilância nos mercados financeiros e de capitais sob empresas que, direta, ou indiretamente, interfiram nesses mercados e em relação às modalidades ou processos operacionais que utilizem, dentre outras inúmeras listadas nos arts. $10 \mathrm{e}$ 11 da Lei n 4.595/64."

Já percebemos, no item (v) acima, o caráter de supervisão complementar que exerce o $\mathrm{BCB}$ e a sua influência sob o sistema financeiro como um todo, não só sobre o sub-sistema bancário. Além das competências acima enumeradas, cabe ao $\mathrm{BCB}$, conforme disposto no art. $9^{\circ}$ da Lei ${ }^{\circ} 4.595 / 64$, fazer cumprir as normas expedidas pelo CMN.

Podem ser citadas ainda diversas competências outorgadas ao BCB por leis especiais, como a de supervisionar sociedades de crédito imobiliário, cooperativas de crédito, empresas de auditoria contábil e auditoria contábil independente, dentre outros ${ }^{40}$.

Já o CMN é órgão do Ministério da Fazenda a quem incumbe formular as diretrizes da política financeira do país. Como órgão político é presidido pelo Ministro da Fazenda e composto pelo Ministro do Planejamento, Orçamento e Gestão e pelo presidente do BCB (o art. $6^{\circ}$ da Lei $n^{\circ} 4.595 / 64$ foi alterado pelo art. $8^{\circ}$ da Lei $n^{\circ}$ 9.609/95, que estabeleceu o Plano Real). Dentre suas atribuições previstas no art. $4^{\circ}$ da Lei $n^{\circ}$ 4.595/64, são mais interessantes ao objeto desse trabalho:

“(i) regular a constituição, funcionamento e fiscalização dos que exercerem atividades subordinadas a Lei $n^{\circ} 4.595 / 64$, bem como a aplicação das penalidades previstas;

(ii) determinar a percentagem máxima dos recursos que as instituições financeiras poderão emprestar a um mesmo cliente ou grupo de empresas;

(iii) estipular índices e outras condições técnicas sobre encaixes, mobilizações e outras relações patrimoniais a serem observadas pelas instituições financeiras;

(iv) expedir normas gerais de contabilidade e estatística a serem observadas pelas instituições financeiras;

(v) delimitar, com periodicidade não inferior a dois anos o capital mínimo das instituições financeiras privadas, levando em conta sua natureza, bem como a localização de suas sedes e agências ou filiais;

\footnotetext{
40 Para todas as competências do BCB, ver: BANCO CENTRAL DO BRASIL. Manual da Supervisão. 
(vi) determinar recolhimento de até $60 \%$ (sessenta por cento) do total dos depósitos e/ou outros títulos contábeis das instituições financeiras, seja na forma de subscrição de letras ou obrigações do Tesouro Nacional ou compra de títulos da Dívida Pública Federal, seja através de recolhimento em espécie, em ambos os casos entregues ao Banco Central do Brasil, na forma e condições que o Conselho Monetário Nacional determinar;

(vi) disciplinar as atividades das Bolsas de Valores e dos corretores de fundos públicos;

(vii) fixar, até quinze (15) vezes a soma do capital realizado e reservas livres, o limite além do qual os excedentes dos depósitos das instituições financeiras serão recolhidos ao Banco Central da República do Brasil ou aplicados de acordo com as normas que o Conselho estabelecer."

Assim sendo, o mercado financeiro em seus sub-mercados de crédito, bancário, monetário e cambial é regulado pelo $\mathrm{CMN}$ em conjunto com o BCB. Enquanto o primeiro estabelece as diretrizes, o segundo as aplica.

A CVM, por sua vez, é o órgão responsável pela regulação do mercado de capitais ou mercado de valores mobiliários. Sua criação e competência vêm estabelecidas na Lei $\mathrm{n}^{\circ}$ 6.385/74 (Lei do Mercado de Capitais) que em seu art. $1^{\circ}$, conforme alterações introduzidas pela Lei ${ }^{\circ}$ 10.303/01, determina:

\footnotetext{
"Art. 1o Serão disciplinadas e fiscalizadas de acordo com esta Lei as seguintes atividades:

I - a emissão e distribuição de valores mobiliários no mercado;

II - a negociação e intermediação no mercado de valores mobiliários;

III - a negociação e intermediação no mercado de derivativos;

IV - a organização, o funcionamento e as operações das Bolsas de Valores;

V - a organização, o funcionamento e as operações das Bolsas de Mercadorias e Futuros;

VI - a administração de carteiras e a custódia de valores mobiliários;

VII - a auditoria das companhias abertas;

VIII - os serviços de consultor e analista de valores mobiliários."
}

Em 2003, além da Lei $n^{\circ} 10.303 / 01$ já referida, foram editadas algumas normas que alteraram a competência e a estrutura da CVM. São elas a MP $\mathrm{n}^{\circ}$ 08/01 (convertida em lei sob o $\mathrm{n}^{\circ} 10.441 / 02$ ) e o Decreto $\mathrm{n}^{\circ}$ 3.995/01. Dentre estas, as mais importantes mudanças foram a outorga de natureza de autarquia especial a CVM e a ampliação do conceito de valores mobiliários. Sobre este último, vale ressaltar que o inciso IX do art. $2^{\circ}$ da 
Lei $\mathrm{n}^{\circ}$ 6.385/74 ampliou consideravelmente o conceito de valores mobiliários, por permitir que a CVM estenda seu manto protetor sobre os quaisquer títulos ofertados publicamente.

No mercado de seguro, capitalização e previdência temos vários órgãos atuando, cada qual com sua especificidade. O Conselho Nacional de Seguros Privados (“CNSP”) é, assim como o CMN, órgão do Ministério da Fazenda com competências normativas gerais e atribuições que podem ser consideradas políticas. Dentre suas competências estão ${ }^{41}$ :

“(i) Fixar as diretrizes e normas da política de seguros privados;

(ii) Regular a constituição, organização, funcionamento e fiscalização dos que exercem atividades subordinadas ao Sistema Nacional de Seguros Privados, bem como a aplicação das penalidades previstas;

(iii) Fixar as características gerais dos contratos de seguros, previdência privada aberta e capitalização;

(iv) Estabelecer as diretrizes gerais das operações de resseguro;

(v) Prescrever os critérios de constituição das Sociedades Seguradoras, de Previdência Privada Aberta e de Capitalização, com fixação dos limites legais e técnicos das respectivas operações; e

(vi) Disciplinar a corretagem do mercado e a profissão de corretor."

A SUSEP, autarquia federal criada pelo Decreto-Lei $n^{\circ} 73 / 66$, é o corpo executivo do CNSP, a quem compete regulamentar e fiscalizar suas normas.

No âmbito do mercado de resseguros, temos o Instituto Brasileiro de Resseguros, criado em 1939. Antes agência reguladora, com a LC 126/07, o IRB se tornou IRB-Brasil Re, corretora de resseguros. A supervisão do mercado de resseguros foi transferida então para o CNSP e para a SUSEP.

Adicionalmente, podemos citar a Agência Nacional de Saúde Suplementar e o Conselho de Saúde Suplementar, entidades cuja atuação foge de nosso âmbito de análise.

\footnotetext{
${ }^{41}$ Cf. site do Ministério da Fazenda, disponível em: http://www.fazenda.gov.br/portugues/orgaos/cnsp/cnspatri.asp.
} 
Em paralelo ao CNSP e à SUSEP, no caso brasileiro, temos o Conselho de Previdência Complementar ("CPC") e a Secretaria de Previdência Complementar ("SPC"), ambos órgãos do Ministério da Previdência e Assistencial Social, a quem incumbe a normatização (CPC), regulamentação, supervisão e fiscalização das entidades fechadas de previdência complementar (SPC).

A essa entidades soma-se o Comitê de Regulação e Fiscalização dos Mercados Financeiro, de Capitais, de Seguros, de Previdência e Capitalização (“COREMEC”) que, segundo Otávio Yazbek ${ }^{42}$, foi criado em função de sobreposições e da multiplicidade de regimes que podem vigorar para uma mesma atividade. O COREMEC foi criado pelo Decreto $\mathrm{n}^{\circ}$ 5.685/06 e, em sua composição, tem representantes de cada um dos órgãos reguladores de cada sub-mercado (BCB, CVM, SUSEP, SPC). É um órgão eminentemente de coordenação, que visa exatamente corrigir as falhas que um sistema funcional da regulação pode ter, a quem compete (Art. $3^{\circ}$ do Dec. $\left.n^{\circ} 5.685 / 06\right)$ :

\footnotetext{
"I - propor a adoção de medidas de qualquer natureza visando ao melhor funcionamento dos mercados sob a regulação e fiscalização das entidades e órgão

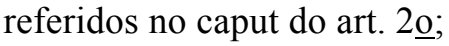

II - debater iniciativas de regulação e procedimentos de fiscalização que possam ter impacto nas atividades de mais de uma das entidades e órgão referidos no caput do art. $2 \underline{0}$, tendo por finalidade a harmonização das mencionadas iniciativas e procedimentos;

III - facilitar e coordenar o intercâmbio de informações entre as entidades e o órgão referidos no caput do art. $2 \underline{\mathrm{o}}$, inclusive com entidades estrangeiras e organismos internacionais;

IV - debater e propor ações coordenadas de regulação e fiscalização, inclusive as aplicáveis aos conglomerados financeiros; e

V - aprovar o seu regimento interno."
}

\footnotetext{
${ }^{42}$ YAZBEK, Otavio. Regulação do Mercado Financeiro e de Capitais. $2^{\mathrm{a}}$ reimpressão. Rio de Janeiro: Elsevier, 2007. p. 190.
} 
Por último, temos o Conselho de Controle de Atividades Financeiras (“COAF”), criado pela Lei n ${ }^{o}$ 9.613/98, órgão do Ministério da Fazenda a quem compete "disciplinar, aplicar penas administrativas, receber, examinar e identificar ocorrências suspeitas de atividade ilícitas relacionada à lavagem de dinheiro"43.

A estrutura para a regulação financeira no Brasil, refletindo aquilo que foi explicado nesse capítulo, ficaria esquematizada da forma abaixo:

Tabela IV - A Estrutura da Regulação Financeira Brasileira

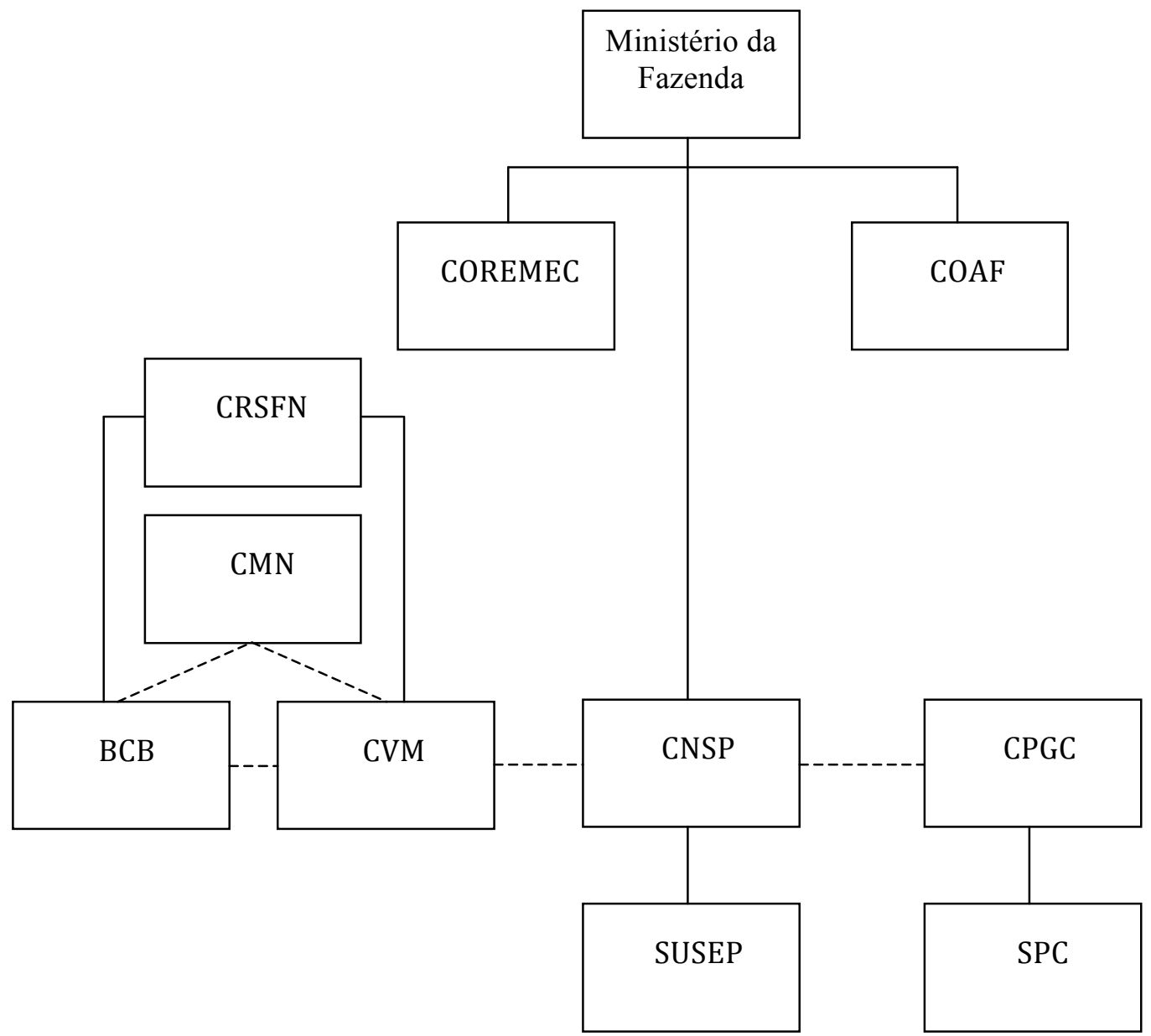

${ }^{43}$ Cf. sítio do COAF, em https://www.coaf.fazenda.gov.br/. 


\section{A crise e a regulação financeira}

Muito se tem falado sobre as causas da crise e a necessidade de reforma do sistema de regulação estatal. São levantados assuntos como a falta de regulação do mercado de CDS, a falta de regulação sobre hedge funds, SPEs e agências de rating, erros na supervisão sobre os modelos de avaliação do risco bancário, dentre outros ${ }^{44}$.

Conforme já mencionado, o próprio Departamento do Tesouro americano editou um guia para a reforma da regulação financeira em que sugere a simplificação e consolidação do complexo sistema americano, através da criação de reguladores por objetivo da regulação (o que se aproxima de um modelo de twin peaks), a saber: um regulador da estabilidade do mercado - o FED, um regulador prudencial e um regulador de condutas. Além destes, haveria um administrador das garantias de depósitos e um regulador de finanças corporativas, que desenvolveria as atividades que hoje são desempenhadas pela $\mathrm{SEC}^{45}$.

Dada a contemporaneidade do tema, esse trabalho não analisará todas as propostas de reforma da regulação financeira (muitas delas ainda em trâmite no congresso americano) mas sim abordará em um de seus aspectos - a regulação dos bancos de investimento - aquilo que nos interessa. Em outra palavras, a partir da análise de uma das falhas apontadas - falha que ocorreu na regulação dos bancos de investimento americano resultante da inabilidade da SEC em regulá-los - se buscará discutir em que ponto e em que medida essa falha poderia ocorrer no sistema pátrio. Mais uma vez, cabe ressaltar que não será abordada a eficácia de normas existentes e se elas impediriam ou não tal falha, mas sim se existe

\footnotetext{
${ }^{44}$ Sobre os erros apontados e propostas de mudança, ver: THE DEPARTMENT OF THE TREASURY. Blueprint for a Modernized Financial Regulatory Structure. Disponível em: http://www.treas.gov/press/releases/reports/Blueprint.pdf. Acesso em 29.10.2009.; Vários. Financial reform: a framwork for financial stability. Publicação do The Group of Thirty. Disponível em: http://www.group30.org/pubs/pub 1460.htm. Acesso em 13.11.2009; KRUGMAN, Paul. How did economists get it so wrong? The New York Times. Sep 6, 2009. Disponível em: http://www.nytimes.com/2009/09/06/magazine/06Economic-t.html. Acesso em 13.11.2009.
} 
competência regulatória para a supervisão prudencial no Brasil que impedisse sua ocorrência.

\subsection{A competência para regular os bancos de investimento nos}

\section{Estados Unidos}

Conforme se viu, as competências regulatórias nos Estados Unidos estão distribuídas por inúmeras agências e órgãos do governo. No caso dos bancos, o Federal Reserve System supervisiona os bancos estaduais membros (por membros se deve entender aqueles que quiseram aderir ao sistema através da norma contida na Sec. 51-36 do Revised Statutes of The United States), as Financial Holding Companies (criadas com o GrammLeach-Blibley Act de 1999) e as Bank Holding Companies (criadas com o Bank Holding Company Act de 1956). O OCC, por sua vez, supervisiona os bancos federais. Assim, inevitável é que se pergunte: mas e os bancos de investimento?

Antes de responder a tal pergunta, contudo, é prudente esclarecer, em síntese, quais as atividades típicas de um banco de comercial e de um banco de investimento.

Os bancos comerciais são os bancos tradicionais, que desenvolvem as atividades de captação de depósitos à vista, livremente movimentáveis, e de depósitos a prazo. Além disso, o bancos comerciais são aqueles que suprem a necessidade de financiamento de uma economia, através de - em sua maioria - mútuos bancários.

Os bancos de investimento, por sua vez, são instituições financeiras especializadas em operações de participação societária de caráter temporário, de financiamento da atividade produtiva para suprimento de capital fixo e de giro e de administração de recursos de terceiros. Não podem, em regra, oferecer serviços de conta corrente e captam recursos via depósitos a prazo, repasses de recursos externos, internos e venda de cotas

\footnotetext{
${ }^{45}$ THE DEPARTMENT OF THE TREASURY. Blueprint for a Modernized Financial Regulatory Structure. Disponível em: http://www.treas.gov/press/releases/reports/Blueprint.pdf. Acesso em 29.10.2009.
} 
de fundos de investimento por eles administrados. Suas principais operações ativas são financiamento de capital de giro e capital fixo, subscrição ou aquisição de títulos e valores mobiliários, depósitos interfinanceiros e repasses de empréstimos externos ${ }^{46}$.

Em segundo lugar, é necessária uma explicação sobre o porquê de não só bancos de investimento, mas também bancos comerciais, terem engajado nas atividades de alto risco que levaram à crise, através de uma curta análise histórica sobre as leis do sistema bancário americano.

Após a crise de 1929, um dos fatores que levou à fraudes foi a falta de segregação que então existia entre as atividades típicas de bancos comerciais e de bancos de investimento. Buscando repelir tais fraudes, foi editado, em 16 de junho de 1933, o Glass-Steagall Act, também conhecido como Banking Act de 1933.

O Glass-Steagall Act, dentre outras medidas, criou o FDIC e separou os bancos americanos por tipo de atividade (comercial ou de investimento), impedindo que houvesse um banco que atuasse em ambas as atividades. Estava instituída a segregação bancária.

Porém, com o crescimento do mercado, em 1999, o governo de George W. Bush promulgou o Gramm-Leach-Blibley Act (também chamado de Financial Services Modernization Act). Essa lei, além de criar a definição de Financial Holding Companies e sujeitá-las à regulação do FED (assim como eram por ele supervisionadas as Bank Holding Companies), revogou inúmeras normas do Glass-Steagall Act e do Bank Holding Company Act. Ao fazê-lo, permitiu que os negócios de banco comercial, banco de investimentos, atividades de seguro e atividades de valores mobiliários fossem concentradas em uma mesma entidade ou em um mesmo grupo financeiro. Estava instituído o broad banking.

Dessa maneira, portanto, bancos comerciais passaram a investir em negócios que antes eram vedados a tal tipo de banco. Além disso, a lei colocou que cada entidade seria supervisionada por seu regulador funcional

\footnotetext{
$\overline{{ }^{46} \text { Cf. sítio do Banco Central do Brasil. }}$
} 
e, ao revogar algumas normas do Glass-Steagall Act, acabou por tornar a supervisão sobre os bancos menos rígida, sendo esse um dos fatores que veio contribuir para a crise.

Voltando aos bancos de investimento, o que se pode apreender da estrutura levantada é que por não serem associados ao Federal Reserve System e não estarem constituídos sob a estrutura de Bank Holding Companies ou Financial Holding Companies, não estavam sujeitos a regulação prudencial. Percebendo isso, a SEC criou o um programa para a supervisão consolidada das entidades que negociam com valores mobiliários, o Consolidated Supervision Entities Program ("CSE").

Segundo a SEC, esse programa faria a supervisão consolidada não somente do operador (broker-dealer) registrado na SEC mas também da holding e de todas as suas afiliadas (como operadores registrados no exterior e entidades desreguladas como os operadores de derivativos). $\mathrm{O}$ programa era desenhado para ser consistente com a supervisão do FED sobre as Bank Holding Companies. Assim, a SEC estaria fazendo uma supervisão prudencial que a permitiria responder rapidamente a uma fraqueza operacional ou financeira de um dos bancos de investimento ou de suas afiliadas não reguladas que poderiam colocar as entidades reguladas, incluindo bancos e operadores registrados no interior, ou o sistema financeiro, em risco.

Os bancos de investimento que aderiram ao CSE foram os então cinco maiores bancos de investimento americanos: Goldman Sachs, Morgan Stanley, Merril Lynch, Lehman Brothers e Bears Stearns.

Embora em vigor, com o passar do tempo e com o advento da crise se percebeu foi que esse programa não funcionava. Nas palavras do então presidente da SEC, Christopher $\operatorname{Cox}^{47}$ :

\footnotetext{
${ }^{47}$ Do original: "As I have reported to the Congress multiple times in recent months, the CSE program was fundamentally flawed from the beginning, because investment banks could opt in or out of supervision voluntarily. The fact that investment bank holding companies could withdraw from this voluntary supervision at their discretion diminished the perceived mandate of the CSE program, and weakened its effectiveness. The Inspector General of the SEC today released a report on the CSE program's supervision of Bear Stearns, and that report validates and echoes the
} 


\begin{abstract}
"conforme eu informei ao Congresso inúmeras vezes nos últimos meses, o programa de CSE era fundamentalmente falho desde o início, porque os bancos de investimento podiam optar por se sujeitar ou não a regulação voluntariamente. $\mathrm{O}$ fato que as holdings de bancos de investimento podiam se desvincular dessa supervisão voluntária conforme julgassem necessário diminuiu o poder de influência do programa CSE e sua efetividade. O Inspetor Geral da SEC publicou hoje um relatório sobre a supervisão feita no modelo CSE sobre o Bear Stearns e esse relatório valida e ecoa as preocupações que eu demonstrei ao Congresso. As maiores conclusões do relatório são em última instância derivadas da falta de competência regulatória específica da SEC ou de qualquer outra agência para atuar como regulador dessas grandes holdings de bancos de investimento".
\end{abstract}

O que aconteceu com o CSE foi que A SEC tentou suprir uma falha regulatória surgida com o Gramm-Leach-Blibley Act: os bancos de investimento não estavam regulados. Por tal iniciativa, a SEC deveria ser aclamada (e não criticada como muitos o fizeram).

No entanto, as falhas desse programa eram inevitáveis: um regulador de condutas estava se aventurando no campo da regulação prudencial sem as informações necessárias (há quem diga que os bancos de investimento impunham o regime de avaliação de risco que lhes era mais conveniente ${ }^{48}$ ) e com um pessoal despreparado para tal tipo de supervisão.

Foi assim que os bancos de investimento se tornaram mais um dos tipos não regulados nos Estados Unidos (juntamente com os hedge funds, as conduits e as SPEs).

Hoje, nos Estados Unidos, tal problema não mais se apresenta na prática: Bear Stearns foi comprado pelo JP Morgan; Lehman Brothers faliu, se fragmentou e teve seus fragmentos adquiridos por outros bancos; Merril Lynch foi comprado pelo Bank of America; Goldman Sachs e Morgan Stanley mudaram seu status para Bank Holding Companies visando a possibilidade de usufruirem da rede de proteção do FED. Assim, os únicos

concerns I have expressed to Congress. The report's major findings are ultimately derivative of the lack of specific legal authority for the SEC or any other agency to act as the regulator of these large investment bank holding companies." Disponível em: http://www.sec.gov/news/press/2008/2008-230.htm

${ }^{48}$ TAYLOR, John B. Ob. Cit. 
dois grandes bancos de investimento ainda existentes nos Estados Unidos atualmente se encontram supervisionados pelo FED.

Isso não quer dizer, no entanto, que não se deve analisar o que ocorreu ou preparar o arcabouço regulatório para evitar falhas como essa. Esta falha na regulação surgida nos Estados Unidos (inclusive em relação aos hedge funds, SPEs, conduits e mercado de $\mathrm{CDS}^{49}$ ) é de extrema importância para que nos preparemos para o futuro.

Inevitavelmente, a regulação vem a posteriori, regulando no presente, problemas do passado. Isso não quer dizer, no entanto, que o mundo não deve estar atento aos problemas que acontecem com seus vizinhos.

Vale ressaltar que não se está aqui a afirmar que a falta de regulação é que causou a crise financeira, pois regular por regular nunca foi a solução para nada. O que se quer dizer é que do ponto de vista da regulação prudencial, pode ter havido uma falha na supervisão tanto dos bancos regulados - que passaram a poder negociar com os chamados ativos tóxicos - quando dos bancos de investimento - pois a regulação da SEC não foi eficaz. Assim, o que se quer dizer é: deixemos a regulação prudencial e sistêmica para quem, tradicionalmente, o faz (por possuir as informações necessárias e o pessoal especializado no assunto). Deixemos que o supervisor prudencial (em sua maioria os Bancos Centrais) regule os bancos, sejam eles de investimento ou não.

O que se entende, no entanto, é que no Brasil tal falha regulatória não existe. Para que se esclareça tal ponto, faz-se necessária, primeiramente, uma análise sobre a regulação prudencial e a evolução da regulação bancária brasileira.

\subsection{A competência para regular os bancos de investimento no Brasil}

O primeiro marco legal da regulação bancária no Brasil foi a lei $n^{\circ}$ 4.595/64, que marca o reconhecimento legal do movimento de expansão 
financeira do país. Tal lei procurou organizar o então existente mercado financeiro, que atuava sob pouquíssima supervisão e que ainda era incipiente $^{50}$. Com ela foram criados o $\mathrm{BCB}$ e o $\mathrm{CMN}$, porém sob estrutura diversa da que hoje os conhecemos.

Então, o BCB era responsável pelas atividades de supervisão do sistema financeiro como um todo, compreendendo inclusive o mercado de capitais e de seguros. Em relação aos bancos, o BCB também supervisionava tanto os bancos de investimento quanto os bancos comerciais, além de todos os outros componentes do sistema financeiro (como as sociedades de crédito, financiamento e investimento - as financeiras, sociedades de crédito imobiliário, dentre outros).

Neste tempo, sua composição era diversificada (e veio sendo alterada diversas vezes até chegar à composição atual), compreendendo o Ministro da Fazenda, os presidentes do Banco do Brasil e do BNDE (atual BNDES) e seis outros membros nomeados pelo Presidente da República, o que denota sua falta de independência política.

Em 14 de julho de 1965, no entanto, foi promulgada a lei $\mathrm{n}^{\circ}$ 4.728/65, que disciplinava o mercado de capitais e cuidava de sua natureza empresarial (e não mais estatal), criando as bases para a regulação de mercado de capitais e o nascimento do mercado de valores mobiliários brasileiro.

A lei $\mathrm{n}^{\circ} 4.728 / 65$ foi alterada pela lei $\mathrm{n}^{\circ} 6.385 / 74$, que criou e delimitou o campo de atuação da CVM em função do conceito de valor mobiliário (ficando para o BCB, no caso de mercado de capitais, apenas a competência residual no que diz respeito aos títulos não definidos na lei como valores mobiliários).

\footnotetext{
${ }^{49}$ Uma nova autoridade regulatória para as instituições financeiras não bancárias (como os hedge funds) está em discussão no Congresso Americano.

${ }^{50}$ Para uma análise sobre a estrutura do mercado financeiro antes de 1964, vide YAZBEK, Otavio. Regulação do Mercado Financeiro e de Capitais. $2^{\mathrm{a}}$ reimpressão. Rio de Janeiro: Elsevier, 2007. p. 255 e ss.
} 
Dias após a publicação da lei $\mathrm{n}^{\circ}$ 6.385/74, seguindo o mesmo movimento de reforma do mercado, foi publicada a lei $n^{\circ} 6.404 / 76$, que estrutura o regime jurídico das companhias abertas e fechadas, sendo este primeiro essencial complemento para a estruturação do mercado de capitais como um todo.

Mais recentemente, em 2001, a lei $\mathrm{n}^{\circ} 10.303 / 01$ veio para, dentre inúmeras reformas na regulação do mercado de valores mobiliários, ampliar seu conceito, alargando o campo de atuação da CVM de maneira amplíssima. Seguindo a definição preconizada pelos americanos, foi alterada a redação do art. $2^{\circ}$ da lei $n^{\circ} 6.385 / 74$ e nele inseridos inúmeros incisos de modo a refletir o conceito amplo de valores mobiliários que hoje encontramos na lei, in verbis:

“Art. 2o São valores mobiliários sujeitos ao regime desta Lei:

I - as ações, debêntures e bônus de subscrição;

II - os cupons, direitos, recibos de subscrição e certificados de desdobramento relativos aos valores mobiliários referidos no inciso II;

III - os certificados de depósito de valores mobiliários;

IV - as cédulas de debêntures;

$\mathrm{V}$ - as cotas de fundos de investimento em valores mobiliários ou de clubes de investimento em quaisquer ativos;

VI - as notas comerciais;

VII - os contratos futuros, de opções e outros derivativos, cujos ativos subjacentes sejam valores mobiliários;

VIII - outros contratos derivativos, independentemente dos ativos subjacentes; e IX - quando ofertados publicamente, quaisquer outros títulos ou contratos de investimento coletivo, que gerem direito de participação, de parceria ou de remuneração, inclusive resultante de prestação de serviços, cujos rendimentos advêm do esforço do empreendedor ou de terceiros."

O que se pode perceber é que, aos poucos, a competência para regular o mercado de valores mobiliários que antes era do BCB foi sendo outorgada à CVM, o que gerou uma especialização de cada um dos órgãos. Ao $\mathrm{BCB}$, atualmente, compete a regulação prudencial do sistema financeiro como um todo, enquanto a CVM cabe a regulação de condutas do mercado de valores mobiliários (ou de capitais). 
Esta separação existente atualmente pode indicar o caminhar da regulação financeira para uma regulação por objetivos (ou de twin peaks). Por outro lado, deve se ter em mente que, no Brasil, existem ainda outros órgãos cuja divisão de competências é dada em função do critério funcional com aspectos institucionais, de modo que tal marcha para um modelo de regulação por objetivos não resta evidente se analisarmos o sistema como um todo.

Especificamente quanto aos bancos no Brasil, percebemos que até a edição da resolução $n^{\circ} 1.524 / 88$, havia a segregação entre as atividades bancárias. Assim como nos Estados Unidos antes do Gramm-Leach-Bibley Act, aqui cada tipo de banco só podia operar com um certo tipo de atividades. Porém, com a resolução ${ }^{\circ}$ 1.524/88 (hoje revogada por falta de aplicabilidade), a segregação deixou de existir. As instituições financeiras em geral poderiam ser constituídas como uma só instituição, ofertante dos mais variados tipos de serviços bancários.

A resolução facultava

\begin{abstract}
"aos bancos comerciais, bancos de investimento, bancos de desenvolvimento, sociedades de crédito imobiliário e sociedades de crédito, financiamento e investimento a organização opcional em uma única instituição financeira, com personalidade jurídica própria, nos termos da legislação em vigor".
\end{abstract}

Criava-se, no Brasil, a figura dos bancos múltiplos, que nada mais eram do que várias instituições financeiras que se congregavam em uma só instituição, com um único balanço, um único caixa, e a conseqüente redução de custos. Este movimento permitiu a expansão do sistema bancário fazendo com que o número de bancos aumentasse em mais que o dobro, atingindo o número de 244 bancos em dezembro de $1994^{51}$.

Assim, de acordo com a resolução, cada tipo de atividade (ou carteira) das instituições financeiras que adotassem a forma da resolução

\footnotetext{
${ }^{51}$ BANCO CENTRAL DO BRASIL. Bancos brasileiros apos a resolução $\mathrm{n}^{\circ}$ 1.524, de 21.09.88. Disponível em http://www.bcb.gov.br/htms/Deorf/e88-2000/texto.asp?idpai=relsfn19882000. Acesso em 09.11.2009.
} 
(banco múltiplo) seria regida pelas regras específicas daquela atividade, emanadas do CMN e supervisionadas e regulamentadas pelo BCB. Desta forma, por exemplo, a carteira comercial dos bancos múltilos era regida pelas normas de bancos comerciais, a carteira de investimento pelas normas de bancos de investimento, e assim sucessivamente ${ }^{52}$.

Inclusive, a própria resolução estabelecia que as instituições teriam acesso a rede de proteção do $\mathrm{BCB}$, que suas reestruturações societárias dependiam de prévia autorização do $\mathrm{BCB}$, entre outros. Em outras palavras: a resolução manteve a competência regulatória do $\mathrm{BCB}$ como ela era anteriormente: se antes o BCB fazia supervisão de cada uma dessas atividades realizadas por instituições diferentes, com a resolução essa supervisão permaneceria, só que desta vez sobre tais atividades realizadas por uma só instituição.

Assim, a separação entre bancos de investimento e bancos comerciais no Brasil deixou de existir de maneira diversa como nos Estados Unidos. Enquanto nos Estados Unidos a permissão para a atuação em diversos segmentos financeiros não foi seguida por uma distribuição de competências coerentes com relação aos bancos de investimento, aqui o contrário aconteceu: todas as instituições financeiras (inclusive bancos comerciais e bancos de investimento) já estavam sob a regulação prudencial do BCB. A nova legislação alterou a organização das instituições, mas manteve a competência regulatória do $\mathrm{BCB}$ que passou a estender seu manto supervisor também sobre as novas instituições: os bancos múltiplos.

Um dos fatores que contribuiu para a inexistência da falha regulatória apontada, no Brasil, é que a nossa lei do mercado financeiro é clara ao estabelecer a competência do $\mathrm{BCB}$ para a supervisão das instituições financeiras. Ao permitir a criação de bancos múltiplos e determinar que seriam regulados de acordo com as normas regentes de cada uma de suas carteiras, o BCB estava apenar exercendo a competência legal

\footnotetext{
52 Cf. FORTUNA, Eduardo. Mercado Financeiro: produtos e serviços. $17^{\mathrm{a}}$ ed. Rio de Janeiro: Qualitymark Editora, 2002.864 p.
} 
a ele atribuída e mantendo e legalidade de sua atuação, corroborando portanto com a eficácia do que diz a lei.

Conforme dito anteriormente, o enfoque do $\mathrm{BCB}$ se dá mais sob o ponto de vista prudencial e sistêmico (embora não deixe de regular condutas), enquanto a CVM é essencialmente um regulador de condutas. Porém, no nosso caso, todas as instituições financeiras estão supervisionadas prudencialmente pelo $\mathrm{BCB}$, e os intermediários pela $\mathrm{CVM}$, o que nos faz crer que, em tese, não haja no Brasil a falha regulatória que houve nos Estados Unidos (ainda que se entenda que lá não houve falha pois a SEC tentou saná-la - saneamento este ineficaz).

Em outras palavras, nos Estados Unidos os bancos de investimento ficaram sem supervisão efetiva. Primeiramente pois a lei que permitiu os bancos múltiplos por lá não foi seguida de uma outorga de competência regulatória a nenhum órgão (e lá não havia essa previsão ampla que desse competência ao banco central para regular todas as instituições financeiras). Em segundo lugar, porque a regulação que a SEC tentou impor de modo a solucionar essa falha foi ineficaz, prorrogando-a.

No Brasil, por outro lado, a competência do BCB é e sempre foi ampla: compete a ele supervisionar todas as instituições financeiras, sejam elas bancos de investimento, bancos comerciais ou os então criados bancos múltiplos. Assim sendo, aqui inexistiria a falha específica apontada nos Estados Unidos: a falta de regulação prudencial efetiva sobre os bancos de investimento.

Sobre esse aspecto, relevante é a separação entre regulador de condutas e regulador prudencial. Isto pois cada regulador tem expertise em uma área e, portanto, deve regulá-la. Vimos um exemplo de falha na regulação quando a SEC adotou o CSE tentando sanar uma falha e acabou por ser culpada por muitos pelo colapso dos bancos de investimento. Assim sendo, se pode concluir pela extrema importância da clareza da lei que deve atribuir competência ampla aos reguladores dentro de seu âmbito de atuação, para que possam bem fazê-lo. Dessa maneira, um regulador de 
condutas não deve regular o sistema prudencialmente, assim como um regulador prudencial não deve regular condutas. 


\section{Conclusão}

Vimos neste trabalho o que ocorreu nos Estados Unidos com a crise do final do século e o que pode ter levado ao colapso do sistema financeiro mundial. Estudamos os modelos teóricos existentes para a supervisão financeira e sua aplicação nos Estados Unidos e no Brasil. Por último, analisamos uma das falhas regulatórias ocorridas com a crise (a regulação dos bancos de investimento), para fazer um paralelo com o sistema brasileiro e entender que, ao menos no que diz respeito à competência para regulá-los, estamos protegidos de falhas.

Ainda que se tenha em vista o clamor popular (e também governamental) por uma regulação estatal mais rígida e internacional, pois entende-se que a preocupação não deve ser no sentido de congruir as diferentes normas de mercado de capitais em normas mundiais, entende-se ser necessário o fortalecimento interno das estruturas regulatórias, para que a soma de fortes mercados internos produza um mercado internacional mais forte e eficiente ${ }^{53}$. Assim, sugere-se que a eficiência de um mercado de capitais não está necessariamente ligada a uma regulação estatal que engesse o mercado e impeça seu desenvolvimento, mas sim em uma regulação consciente, preparada, bem estruturada.

Sobre esse aspecto, devemos entender que embora em tese estejamos protegidos dessa falha específica, na realidade podemos não estar. Isso pois uma boa supervisão não se faz apenas da existência de competência regulatória, mas também de normas claras, precisas e eficazes. Precisamos fortalecer nosso sistema de supervisão como um todo, em todos os seus aspectos (normativo, fiscalizador e punitivo).

Os eventos que ocorreram nos últimos anos devem ser estudados, analisados, dissecados, e servir de exemplo para que os reguladores possam identificar as falhas eventualmente existentes e preparar-se para as futuras crises. Não é necessário que as crises ocorram, os sistemas entrem em

\footnotetext{
${ }^{53}$ Nesse sentido, vide RODNIK, Dani. A plan B for global finance. The Economist, v. 390, n. 8622 , p. 80, mar. 2009.
} 
colapso, para se possa com elas aprender. Devemos olhar para o lado, analisar o caso concreto e proteger nossas instituições. Afinal, nas palavras de Haghuram Rajan ${ }^{54}$ : crises virão, estejamos preparados para a próxima bolha!

${ }^{54}$ RAJAN, Raghuram G. Recriando o sistema financeiro. Apresentação feita no $4^{\circ}$ Congresso Internacional do Mercado Financeiro e de Capitais BM\&F Bovespa. Disponível em: http://www.bmf.com.br/portal/pages/congresso/2009/apresentacoes.asp Acesso em 09.11.2009. 


\section{Referências Bibliográficas}

ALTIG, David. A nova regulação para gerenciamento de riscos de crédito pós-crise subprime. Apresentação feita no 4o Congresso Internacional do Mercado Financeiro e de Capitais, organizado pela BM\&F Bovespa. Campos do Jordão, São Paulo, em 29.08.2009. Disponível em http://www.bmf.com.br/portal/pages/congresso/2009/apresentacoes.asp. Acesso em 09.11.2009.

ARAGÃO, Alexandre dos Santos de. Regulação da Economia: Conceito e Características Contemporâneas. In: Revista de Direito da Associação dos Procuradores do Novo Estado do Rio de Janeiro, vol. XI - Direito da Regulação. Rio de Janeiro: Lúmen Juris, 2002. p. 3-68.

- O Conceito Jurídico de Regulação da Economia. In: Revista de Direito Mercantil, $\mathrm{n}^{\mathrm{o}}$ 122. Rio de Janeiro: Revista dos Tribunais.

BANCO CENTRAL DO BRASIL. Manual da Supervisão. Disponível em https://www3.bcb.gov.br/gmn/visualizacao/listarDocumentosManualPublic

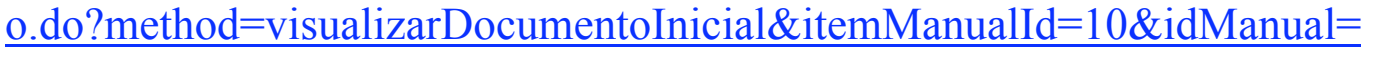
1. Acesso em 28.10.2009.

BANCO CENTRAL DO BRASIL. Bancos brasileiros após a resolução n 1.524, de 21.09.88. Disponível em http://www.bcb.gov.br/htms/Deorf/e88-

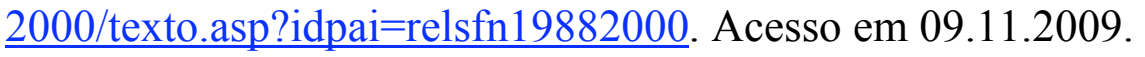

BARTH, James R., NOLEE, Daniel E., PHUMIWASANA, Triphon, e YAGO, Glenn. A cross-country analisis of the bank supervisory framework and bank performance. Disponível em http://papers.ssrn.com/sol3/papers.cfm?abstract $\mathrm{id}=325061$. Acesso em 14.10.2009. 
BRUNNERMEIER, Markus K. Deciphering the liquidity and credit crunch. Disponível em: http://www.nber.org/papers/w14612.

CHEDIAK, Julian Fonseca Peña. A reforma do mercado de valores mobiliários. In: Jorge Lobo (coord.). Reforma da Lei das Sociedades Anônimas. Rio de Janeiro: Forense, 2002.

COFFEE JR, John C.; SALE, Hillary A. Redesigning the SEC: does the Treasury have a better idea? Dísponível em: http://ssrn.com/abstract=1310866. Acesso em 27.03.2009.

COLBY, Robert. Depoimento proferido perante o Comitê de Serviços Financeiros da Câmara dos Deputados Americana sobre a supervisão consolidada das Empresas de Valores Mobiliários e suas sociedades afiliadas de empréstimo industrial. Disponível em: http://www.sec.gov/news/testimony/2007/ts042507rc.htm. Acesso em 05.11.2009.

EIZIRIK, Nelson et al.. Mercado de capitais: regime jurídico. $2^{\mathrm{a}}$ ed. Rio de Janeiro: Renovar, 2008. 624 p.

. O papel do estado na regulação do mercado de capitais. Rio de Janeiro: IBMEC, 1977.

. Reforma das S.A. e do Mercado de Capitais. $2^{\mathrm{a}}$ ed. Rio de Janeiro: Renovar, 1998.

FRATIANNI, Michele U.. Financial Crises, Safety Nets and Regulation. Disponível em: http://ssrn.com/abstract=1286903 
FORTUNA, Eduardo. Mercado Financeiro: produtos e serviços. $17^{\mathrm{a}}$ ed. Rio de Janeiro: Qualitymark Editora, 2002. 864 p.

GORTON, Gary B. Information, Liquidity and the (ongoing) panic of 2007. Disponível em: http://www.nber.org/papers/w14649.

HELLWIG, Martin. Systemic risk in the financial sector: an analysis of the subprime-mortgage financial crisis. Disponível em: http://www.coll.mpg.de/abst2008_43.html. Acesso em 27.03.2009.

HERTOG, Johan Den. General Theories of Regulation. In: Boude Wijn Bouckaert, Gerrit De Geest. In: Enciclopedia of Law and Economics, v. 3, Cheltenham, Edward Elgar Publishing Limited, 2001. Disponível em http://igitur-archive.library.uu.nl/law/2007-0221201358/hertog_99_generaltheoriesofregulation.pdf. Acesso em 29.09.2009.

KISTLER, Henri Eduard Stupakoff. Brasil, a caminho de um regulador único para o sistema financeiro? Uma análise das diferentes estruturas de supervisão governamental dos mercados financeiros, de seguros e de capitais existentes no mundo. Dísponível em: http://www.cvm.gov.br/port/public/publ/Art_300.asp. Acesso em 20.08.2009.

KRUGMAN, Paul. How did economists get it so wrong? The New York Times. Sep 6, 2009. Disponível em: http://www.nytimes.com/2009/09/06/magazine/06Economic-t.html. Acesso em 13.11.2009.

MAYER, Christpher J., PENCE, Karen. Subprime mortgages: what, where and to whom? Disponível em: http://www.nber.org/papers/w14083 
PEREIRA, Caio Mário da Silva. Instituições de Direito Civil. Direitos Reais. $19^{\mathrm{a}}$ ed. Rio de Janeiro: Forense, 2007. 467 p.

QUEIROZ, José Eduardo Carneiro. O conceito de valor mobiliário e a competência da Comissão de Valores Mobiliários e do Banco Central do Brasil. In: Aspectos Atuais do Direito do Mercado Financeiro e de Capitais. Editora Dialética, 1999.

RAJAN, Raghuram. Recriando o sistema financeiro. Apresentação feita no 4o Congresso Internacional do Mercado Financeiro e de Capitais, organizado pela BM\&F Bovespa. Campos do Jordão, São Paulo, em 29.08.2009. Disponível em http://www.bmf.com.br/portal/pages/congresso/2009/apresentacoes.asp. Acesso em 09.11.2009.

RODNIK, Dani. A plan B for global finance. The Economist, v. 390, n. 8622, p. 80, mar. 2009. Ec

SALOMÃO FILHO, Calixto. Regulação da atividade econômica (princípios e fundamentos jurídicos). $2^{\mathrm{a}}$ ed. São Paulo: Malheiros, 2008.

SOUTO, Marcos Juruena Villela. Direito Administrativo Regulatório. $2^{\mathrm{a}}$ ed. Rio de Janeiro, São Paulo, Brasília e Rio Grande do Sul: Lúmen Juris, 2005.

TAYLOR, John B. The financial crisis and the policy responses: an empirial analysis of what went wrong. Disponível em: http://www.nber.org/papers/w14631. Acesso em 27.03.2009. 
THE DEPARTMENT OF THE TREASURY. Blueprint for a Modernized Financial Regulatory Structure. Disponível em: http://www.treas.gov/press/releases/reports/Blueprint.pdf. Acesso em 29.10.2009.

TRINDADE, Marcelo., SANTOS, Aline de Menezes. Regulação e autoregulação no Brasil e a crise internacional. Disponível em: http://www.bmfbovespa.com.br/juridico/download/Artigo MarceloTrindad e.pdf. Acesso em 01.11.2009.

Vários. The structure of financial supervision: approaches and challenges in a global marketplace. Publicação do The Group of Thirty. Disponível em: http://www.group30.org/pubs/GRP30_FRS ExecSumm.pdf. Acesso em 27.03.2009.

Vários. Financial reform: a framework for financial stability. Publicação do The Group of Thirty. Disponível em: http://www.group30.org/pubs/pub 1460.htm. Acesso em 13.11.2009.

YAZBEK, Otavio. Regulação do Mercado Financeiro e de Capitais. $2^{\mathrm{a}}$ reimpressão. Rio de Janeiro: Elsevier, 2007. 316 p.

ZINGALES, Luigi. The Future of Securities Regulation. Disponível em: http://ssrn.com/abstract=1319648. Acesso em 27.03.2009. 